2015

\title{
Creating New Pathways to Justice Using Simple Artificial Intelligence and Online Dispute Resolution
}

Darin Thompson

Osgoode Hall Law School of York University, darinmobile@gmail.com

Follow this and additional works at: http:// digitalcommons.osgoode.yorku.ca/olsrps

Part of the Law Commons

\section{Recommended Citation}

Thompson, Darin, "Creating New Pathways to Justice Using Simple Artificial Intelligence and Online Dispute Resolution" (2015).

Osgoode Legal Studies Research Paper Series. 152.

http://digitalcommons.osgoode.yorku.ca/olsrps/152 


\title{
OSGOODE HALL LAW SCHOOL \\ LEGAL STUDIES RESEARCH PAPER SERIES
}

\section{Creating New Pathways to Justice Using Simple Artificial Intelligence and Online Dispute Resolution International Journal of Online Dispute Resolution, Vol. 1 (2), 2015.}

\section{Darin Thompson}

This paper can be downloaded free of charge from: http://ssrn.com/abstract=2696499

\begin{abstract}
Further information and a collection of publications from the Osgoode Hall Law School Legal Studies Research Paper Series can be found at:

http://www.ssrn.com/link/Osgoode-Hall-LEG.html
\end{abstract}

\section{Editors:}

Editor-in-Chief: Carys J. Craig (Associate Dean of Research \& Institutional Relations and Associate Professor, Osgoode Hall Law School, York University, Toronto)

Production Editor: Kiana Blake (Osgoode Hall Law School, York University, Toronto) 
Osgoode Legal Studies Research Paper No. 27

Vol. 12/ Issue. 6/ (2016)

\title{
Creating New Pathways to Justice Using Simple Artificial Intelligence and Online Dispute Resolution
}

International Journal of Online Dispute Resolution, Vol. 1 (2), 2015.

Darin Thompson

\begin{abstract}
:
Access to justice in can be improved significantly through implementation of simple artificial intelligence (AI) based expert systems deployed within a broader online dispute resolution (ODR) framework. Simple expert systems can bridge the 'implementation gap' that continues to impede the adoption of AI in the justice domain. This gap can be narrowed further through the design of multi-disciplinary expert systems that address user needs through simple, non-legalistic user interfaces. This article provides a non-technical conceptual description of an expert system designed to enhance access to justice for nonexperts. The system's knowledge base would be populated with expert knowledge from the justice and dispute resolution domains. A conditional logic rule-based system forms the basis of the inference engine located between the knowledge base and a questionnairebased user interface. The expert system's functions include problem diagnosis, delivery of customized information, self-help support, triage and streaming into subsequent ODR processes. Its usability is optimized through the engagement of human computer interaction (HCI) and effective computing techniques that engage the social and emotional sides of technology. The conceptual descriptions offered in this article draw support from empirical observations of an innovative project aimed at creating an expert system for an ODR-enabled civil justice tribunal.
\end{abstract}

\section{Keywords:}

Artificial intelligence, AI, online dispute resolution, ODR, expert system, justice, access to justice, legal information technology, knowledge base, knowledge engineering, pathway, affective computing, human computer interaction, $\mathrm{HCl}$, self-help, triage

\section{Author(s):}

Darin Thompson

Osgoode Hall Law School and University of Victoria faculty of Law

E: darinmobile@gmail.com 


\title{
Creating New Pathways to Justice Using Simple Artificial Intelligence and Online Dispute Resolution*
}

\author{
Darin Thompson $^{* *}$
}

\begin{abstract}
Access to justice in can be improved significantly through implementation of simple artificial intelligence (AI) based expert systems deployed within a broader online dispute resolution (ODR) framework.

Simple expert systems can bridge the 'implementation gap' that continues to impede the adoption of AI in the justice domain. This gap can be narrowed further through the design of multi-disciplinary expert systems that address user needs through simple, non-legalistic user interfaces.

This article provides a non-technical conceptual description of an expert system designed to enhance access to justice for non-experts. The system's knowledge base would be populated with expert knowledge from the justice and dispute resolution domains. A conditional logic rule-based system forms the basis of the inference engine located between the knowledge base and a questionnaire-based user interface.

The expert system's functions include problem diagnosis, delivery of customized information, self-help support, triage and streaming into subsequent ODR processes. Its usability is optimized through the engagement of human computer interaction (HCI) and affective computing techniques that engage the social and emotional sides of technology.

The conceptual descriptions offered in this article draw support from empirical observations of an innovative project aimed at creating an expert system for an ODR-enabled civil justice tribunal.
\end{abstract}

Keywords: expert system, online dispute resolution, artificial intelligence, access to justice, legal information technology.

* Thanks to Prof. Burkhard Schafer for his guidance in the preparation of this work in its original format, which was submitted as the author's LLM dissertation at the University of Edinburgh in 2013.

** Legal Counsel, BC Ministry of Justice; Adjunct Law Professor, University of Victoria; Adjunct Law Professor, Osgoode Hall Law School. Email: darinmobile@gmail.com. 
Imagine a young college student, struggling to keep up with student loan payments, living and entertainment expenses, being lured by a payday lender into a loan she cannot afford. Almost immediately, she defaults on her payments. She soon receives letters from the lender threatening to turn her file over to a collections agency or to a lawyer who will sue her. The young student cannot afford to hire her own lawyer, and if she could, the costs would outweigh the value of the debt. She searches for help on public legal information websites, but immediately faces 'information overload.' She does not understand the situation well enough to know which of the countless guidebooks apply to her situation. Most of the information explains complex court procedures, but she has not been sued yet. The woman knows she needs to do something, but has no idea how to take action.

This article offers a conceptual overview for an artificial intelligence (AI)based system designed to support non-experts in the justice context. In a departure from current justice resources that focus on information or explanations of legal forms and procedures, this system offers dynamic functionality and dispute resolution support informed by expert knowledge. This proposal also departs from prior applications of AI in the justice domain by adopting simpler technology, modest aims and a user-centric approach. For the purposes of this article, the conceptual system is called the Justice Pathway Expert System (JPES).

Successful implementation of the JPES would create new pathways into the justice system for non-expert users, and become a tool for online dispute resolution (ODR). In striking a balance between simplicity and utility, the system could bridge the 'implementation gap' currently preventing widespread adoption of AI technologies within the justice domain. In the current context of access to justice challenges, this technology could become part of a timely and efficient solution. Accordingly, much of this article concerns practical aspects of the JPES, including its functionality and methods for acquiring its expert knowledge.

To further address the implementation gap that has prevented widespread adoption of AI systems in this field, an introductory analysis of the way humans interact with computers is also offered in support of the conceptual proposal.

\subsection{Organization of Article}

The remainder of this article is organized as follows. Part 2 outlines research methods. Next, Part 3 considers technology and access to justice issues. Part 4 reviews past usage of $\mathrm{AI}$ in the justice domain, and is followed by a discussion of expert systems in Part 5. Part 6 describes the JPES's components and functions, while Part 7 outlines methods for capturing and structuring the expert knowledge. Part 8 advances the notion of usability with a sample of emotional intelligence functions and reflections on the way humans interact with computers followed by the conclusion in Part 9 . 
This research was driven by my own empirical observations while working within a formal civil justice system, where considerable energy is spent developing responses to the challenge of access to justice in a fiscal environment of resource scarcity. It includes analyses of, and comparisons with, other concepts and initiatives describing various technologies ${ }^{1}$ and $\mathrm{AI}^{2}$ as potential solutions. My personal observations, combined with academic research in this area, ${ }^{3}$ led me to conclude that while some technology solutions do not go far enough to present meaningful change, many AI-based solutions were too ambitious or theoretical and, therefore, failed to meet the needs of users. ${ }^{4}$ I chose to deviate from these past approaches and to conceptualize a system that is advanced in terms of technology and processes, but relatively simple in AI terms.

My research is augmented by systematic participation observation in a project under way with the British Columbia (B.C.) Ministry of Justice. In particular, I have interacted with subject matter experts from different problem domains, public legal education and information providers, senior justice analysts, technical contractors, user experience design experts, tribunal members, law society representatives and mediators.

My description of the JPES is meant to contribute to literature concerned with the disciplines of information technology, law and ODR. These descriptions are offered at a conceptual level and are neither strictly legalistic nor technocratic. Part of this effort is concerned with taking concepts from academic literature, combining them with legal and ODR expertise and creating visual knowledge that is interpreted differently, and in some cases, more effectively, than text. ${ }^{5}$ I support this objective through visual representations or original 'screenshots' created specifically for this purpose. Because my proposal pursues a practical orientation to address the needs of users, the disciplines of human-computer interaction and affective computing are also incorporated in my description.

My methodological approach is subject to several limitations. Considerable work will be required to develop the JPES technology, including identification of technical requirements, coding and construction of software architecture and a user interface. Moreover, the validity of my proposals will depend on user testing. Empirical research, for measures like uptake rates, user satisfaction and outcomes

1 For a current summary of many examples of uses of technology to enhance access to justice, the reader is directed to: Cabral et al., 'Using Technology to Enhance Access to Justice', Harvard Journal of Law \& Technology, Vol. 26, No. 1, 2012, p. 243.

2 For a broad survey and accompanying critique of AI systems in the justice domain, see J. Popple, A Pragmatic Legal Expert System, Dartmouth, England, 1996, pp. 2-50. Retrieved on 29 November 2012 from <http://cs.anu.edu.au/ James.Popple/publications/books/shyster.pdf〉.

3 My academic research in this area includes coursework and writing towards the degree of an LLM at the University of Edinburgh School of Law.

4 For a fuller discussion, see B. Schafer, 'ZombAIs: Legal Expert Systems as Representatives "Beyond the Grave", SCRIPTed, Vol. 7, No. 2, 2010, p. 384. Retrieved on 2 January 2013 from <www.law.ed.ac.uk/ahrc/script-ed/vol7-2/schafer.asp>; see also Popple, 1996, pp. 49-50.

5 B. Schafer, 'Can You Have Too Much of a Good Thing? A Comment on Bart Verheij's Legal Argumentation Support Software', Law, Probability and Risk, Vol. 6, 2007, pp. 209, 212. 
will also be required. Finally, an operational form of the JPES may give rise to the need for further legal analysis on issues ranging from jurisprudential considerations ${ }^{6}$ to practical risks such as the unauthorized practice of law. ${ }^{7}$

Before describing the JPES and its functions, this section briefly considers the potential for technology to increase access to justice. While the JPES could apply to a range of case types, the following discussion is framed within the context of civil disputes generally. ${ }^{8}$

\subsection{Technology and Access to Justice}

It has long been predicted that technological advances in areas like communication, business and entertainment would bring similar modernizations to our justice systems. Most of these predictions have proved too optimistic. ${ }^{9}$ Many attempts to induce change through technology-based projects have attained only moderate improvements, or even failures. ${ }^{10}$

A contributing factor to the slow pace of technological change in the justice sector ${ }^{11}$ is the historical preference for top-down, court and lawyer-centric approaches. ${ }^{12}$ Changes like electronic filing or searchable judgment databases primarily use technology to automate existing justice processes, addressing the needs, and fitting within the tolerances, of justice providers like lawyers and judges.

Inspiration for the JPES is drawn from more transformative use of technology. Emerging 'disruptive technologies' hold the potential to challenge and replace traditional legal processes rather than simply complement them. ${ }^{13}$ Fur-

6 R. Susskind, 'Expert Systems in Law: A Jurisprudential Approach to Artificial Intelligence and Legal Reasoning', Modern Law Review, Vol. 49, No. 2, 1986, pp. 168, 184-194.

7 See, e.g., Cabral et al., 2012, pp. 317-324; C. Johnson, 'Leveraging Technology to Deliver Legal Services', Harvard Journal of Law \& Technology, Vol. 23, No. 1, 2009, pp. 259, 269-270.

8 See The World Justice Project, 'Civil Justice'. Retrieved on 15 July 2013 from <http:// worldjusticeproject.org/factors/effective-civil-justice>.

9 R.W. Staudt, 'All the Wild Possibilities: Technology That Attacks Barriers to Access to Justice', Loyola of Los Angeles Law Review, Vol. 42, No. 4, 2009, pp. 1117, 1121-1122.

10 Id., pp. 1121-1122.

11 See, e.g., R. Susskind, 'Legal Informatics - A Personal Appraisal of Context and Progress', European Journal of Law and Technology, Vol. 1, No. 1, 2010. Retrieved on 10 July 2013 from <http:// ejlt.org/article/view/18/7>.

12 C.B. Robertson, 'The Facebook Disruption: How Social Media May Transform Civil Litigation and Facilitate Access to Justice', Arkansas Law Review, Vol. 65, 2012, p. 75.

13 R. Susskind, The End of Lawyers?: Rethinking the Nature of Legal Services, Oxford University Press, New York, 2008, p. 275. 
ther innovations are also reaching the justice domain through emerging ODR technologies. ${ }^{14}$

While it is beyond the scope of this article to detail the extent of access to justice challenges, ${ }^{15}$ there is growing recognition that ordinary people are the true users of the justice system, and those who exhibit the highest need. ${ }^{16}$ Yet, justice processes remain tightly controlled by system providers.

Technology holds the potential to open up justice to new actors and competitors who do not come from the traditional institutional framework. ${ }^{17}$ While justice providers may continue to resist such changes, users who are more concerned with affordability and access will welcome them. Cassandra Burke Robertson contends that individuals with unmet legal needs may actually drive the coming disruptions to legal practice brought about by new technologies. ${ }^{18}$ Whether or not future innovations are top-down or user-driven, the proposals contained in this article accept that technology has a critical role to play in enhancing access to justice. $^{19}$

\subsection{The Non-Lawyer User}

The targeted users for the JPES are non-lawyers, who in this case are held to lack justice and dispute resolution knowledge and skills commensurate with experts in

14 R. Susskind, 'Introduction', in M.A. Wahab, E. Katsh \& D. Rainey (Eds.), Online Dispute Resolution: Theory and Practice, A Treatise on Technology and Dispute Resolution, Eleven International Publishing, The Hague, 2012, pp. v-vi. For examples of ODR in legislation, see the B.C. Civil Resolution Tribunal Act, Bill 44 - 2012. Retrieved on 10 August 2013 from <www.leg.bc.ca/39th4th/ 1st_read/gov44-1.htm>; Council Reg. 524/2013, OJ 2013 L 165/1 on online dispute resolution for consumer disputes and amending Reg. (EC) 2006/2004 and Directive 2009/22/EC (Regulation on consumer ODR).

15 See, e.g., J. McHale, QC, 'Access to Justice, a Government Perspective', University of New Brunswick Law Journal, Vol. 63, 2012, p. 352; Remarks of the Right Honourable B. McLachlin, PC, 'The Challenges We Face', Presented at the Empire Club of Canada, Toronto, 8 March 2007. Retrieved on 28 July 2013 from <www.scc-csc.gc.ca/court-cour/judges-juges/spe-dis/bm-2007-03-08-eng. aspx>; K. Roach \& L. Sossin, 'Access to Justice and Beyond', University of Toronto Law Journal, Vol. 60, 2010, p. 373.

16 See, e.g., Civil Justice Council, 'Access to Justice for Litigants in Person (or Self-represented Litigants): A Report and Series of Recommendations to the Lord Chancellor and to the Lord Chief Justice', 2011. Retrieved on 3 May 2015 from <www.judiciary.gov.uk/wp-content/uploads/2014/ 05/report-on-access-to-justice-for-litigants-in-person-nov2011.pdf >; J. Macfarlane, 'Final Report, The National Self-Represented Litigants Project: Identifying and Meeting the Needs of Self-Represented Litigants', 2013. Retrieved on 5 May 2015 from <https://static1.squarespace.com/ static/511bd4e0e4b0cecdc77b114b/t/5473a3cde4b07dc0643994be/1416864717309/Self-repres ented_project.pdf>.

17 D. Mountain, 'Could New Technologies Cause Great Law Firms to Fail?', Syracuse Law Review, Vol. 52, 2002, pp. 1065, 1073.

18 Robertson, 2012, p. 75.

19 See Cabral et al., 2012, p. 317; M.J. Wolf, 'Collaborative Technology Improves Access to Justice', New York University Journal of Legislation and Public Policy, Vol. 15, No. 3, 2012, p. 759; Standing Council on Law and Justice (Australia), 'Analysis Paper: Harnessing the Benefits of Technology to Improve Access to Justice', 2012. Retrieved on 5 May 2015 from <www.lccsc.gov.au/ agdbasev7wr/sclj/harnessing_the_power_of_technology_analysis_paper.pdf >; Susskind, 2008, pp. 230-238. 
this domain. These people are often labeled as unrepresented ${ }^{20}$ or self-represented litigants. ${ }^{21}$ However, these terms hold a bias towards litigation and courts, obscuring other approaches to dispute management and resolution in a larger framework of justice and ODR. To maintain a focus on user needs rather than on traditional court processes, the rest of this article will use the term 'user' with the understanding that it refers to non-lawyers, and with respect to the domain, to non-experts.

Future versions of the JPES could be constructed to assist paralegals or even to function at the level of an expert adviser for lawyers. However, this article acknowledges that such systems have been tried with limited success, ${ }^{22}$ and that it may be some time before breakthroughs emerge on this level. ${ }^{23}$

\subsection{Entries to Justice through Technology}

The JPES would serve as an initial point of contact for users engaging with the justice system. The 'pathway' metaphor is meant to suggest guidance, informed by users' individual needs or issues, leading to the right resources. The JPES is technology-based and accessible via the Internet through an intelligent questionnaire interface.

'Online interview' products, like the A2J Author, ${ }^{24}$ have been in development since at least $2004 .{ }^{25}$ These applications pose questions to the user, and take subsequent steps based on responses or inputs. However, many of these technologies are designed primarily as document assembly tools to guide users into court processes, ${ }^{26}$ as opposed to moving them towards dispute management and resolution. In this respect, these products are complementary to traditional justice processes, and distinguishable from systems like the JPES that create entirely new services and processes.

More advanced models have also been tried. Darryl Mountain noted that despite the failures of earlier, more ambitious AI initiatives, work continues towards the creation of legal Web advisers. ${ }^{27}$ According to Mountain, a legal Web adviser relies upon AI to provide legal advice through computers. ${ }^{28}$ These systems are designed to collect facts from users through interview-style approaches and produce answers based on a decision-tree analysis. ${ }^{29}$ As will be shown below, the JPES follows a similar model, but with a less legalistic focus. JPES outputs may include legal advice, but only if it incidentally forms a component of the larger bundle of guidance in the specific circumstances for the users.

20 Civil Justice Council, 2011, p. 13.

21 Cabral et al., 2012, pp. 258-259.

22 Schafer, 2010, p. 386.

23 Mountain, 2002, pp. 1080-1081.

24 See 'A2J Author', a system created by the Chicago-Kent College of Law, available from <www. kentlaw.iit.edu/institutes-centers/center-for-access-to-justice-and-technology/a2j-author > .

25 Chicago-Kent College of Law, 'History \& Research'. Retrieved on 5 May 2013 from <www. kentlaw.iit.edu/institutes-centers/center-for-access-to-justice-and-technology/history>.

26 Staudt, 2009, p. 1131.

27 Mountain, 2002, p. 1065.

28 Id., pp. 1065-1066.

29 Id., p. 1066. 


\subsection{Broadening the Approach to Justice}

Within many justice systems, inertia pulls all things towards litigation. Many reform efforts, including those aimed at increasing access to justice, reflect this inertia. Yet, this focus is almost entirely misplaced. Few citizens, including those who engage with justice systems, will ever be in a trial. In the USA, fewer than $2 \%$ of civil cases filed will be adjudicated in court. ${ }^{30}$ In B.C., fewer than $3 \%$ of civil cases make it to trial. ${ }^{31}$ Despite assertions that low trial rates correspond to high settlement rates, many cases never make it to trial due to default or abandonment. ${ }^{32}$ Equally important is unmet demand, or the high volumes of justiciable disputes that never enter the formal justice system to begin with. ${ }^{33}$ Whether because of cost, complexity or delay, many users do not take the first steps into the formal justice system.

By shifting orientation to the first point of contact with the justice system, it becomes possible to support the vast majority of cases that never make it to trial. A computer-based system that relies on relatively simple AI can begin to serve this majority of citizens in an efficient and timely way. In this regard, the JPES must not be seen as a tool for automating existing processes. In the business world, technology is already being used to help organizations break away from antiquated and functionally obsolete practices. ${ }^{34}$ Systems like the JPES could similarly help to spring justice systems from past into present.

An ancillary goal for the JPES is to address the emotional or social experiences of its users. While this article does not purport to create a framework for gathering or analysing psychological data, it accepts that emotional and social aspects of disputes are worthy of consideration. Although traditional justice stakeholders tend to argue that user satisfaction with dispute resolution processes are determined by the outcome, psychological research suggests that people put considerable weight on their own reactions to the process. ${ }^{35}$ At the very least, the JPES should be designed to work for users who are negatively affected by their emotional states. ${ }^{36}$

30 J.H. Langbein, 'The Disappearance of Civil Trial in the United States', Yale Law Journal, Vol. 122, No. 3, 2012, p. 522. Retrieved on 5 May 2015 from <www.yalelawjournal.org/article/thedisappearance-of-civil-trial-in-the-united-states $>$.

31 British Columbia Justice Reform Working Group, 'Effective and Affordable Civil Justice: Report of the Civil Justice Reform Working Group to the Justice Review Task Force', 2006, p. 2, n. 3. Retrieved on 5 May 2013 from <www.ag.gov.bc.ca/public/bcjusticereview/cjrwg_report_11_06. pdf>.

32 C. Baar, 'The Myth of Settlement', 1999, Unpublished paper prepared for delivery at the Annual Meeting of the Law and Society Association, Chicago, Illinois. Retrieved on 5 May 2015 from <http://siteresources.worldbank.org/INTLAWJUSTINST/Resources/MythofSettlement.pdf〉.

33 A. Currie, 'The Legal Problems of Everyday Life - The Nature, Extent and Consequences of Justiciable Problems Experienced by Canadians', 2009, Report prepared for the Department of Justice Canada. Retrieved on 5 May 2015 from <www.justice.gc.ca/eng/rp-pr/csj-sjc/jsp-sjp/rr07_la1rr07_aj1/rr07_la1.pdf>.

34 M. Hammer, 'Reengineering Work: Don't Automate, Obliterate', Harvard Business Review, JulyAugust 1990, p. 104.

35 T. Tyler, 'The Psychology of Disputant Concerns in Mediation', Negotiation Journal, Vol. 3, No. 4, 1987, p. 367.

36 Macfarlane, 2013, p. 64. 
The potential for AI-based systems to enhance access to justice has already been recognized in the justice and ODR contexts. ${ }^{37}$ This section provides a general introduction to AI-based expert systems, and a brief analysis of past initiatives.

\subsection{General Introduction to AI}

In general terms, AI creates synthetic intelligence through technology. ${ }^{38}$ While some work in this area has attempted to create machines that replicate patterns of human thought, ${ }^{39}$ many systems seek only to provide outputs or perform tasks drawing on human intelligence. ${ }^{40}$ In the latter format, outcomes may reflect human intelligence, even if the reasoning process does not resemble human thought. These AI systems ultimately represent tools that can have a profound impact on our thinking or reasoning processes. ${ }^{41}$

Distinctions among AI systems are also made according to reasoning methods. AI may employ deductive reasoning, case-based analyses ${ }^{42}$ or hybrids. ${ }^{43}$ Some AI more closely resembles sophisticated reasoning methods intended to simulate human thought through reliance on neural networks. ${ }^{44}$ In contrast, the JPES employs a much simpler, basic form of deductive reasoning, described in more detail in later sections.

\subsection{Earlier Approaches to AI in the Legal Domain}

The earliest efforts to apply AI in the legal context date back at least to $1970 .{ }^{45}$ Many attempts were ambitious in terms of complexity and capabilities. ${ }^{46}$ Some initiatives sought to create computerized judges that could perform complex legal

37 A.R. Lodder \& J. Zeleznikow, 'Developing an Online Dispute Resolution Environment: Dialogue Tools and Negotiation Support Systems in a Three-Step Model', Harvard Negotiation Law Review, Vol. 10, 2005, pp. 287, 296. Retrieved on 2 January 2013 from <http://papers.ssrn.com/sol3/ papers.cfm?abstract_id=1008802>.

38 D. Poole, A. Mackworth \& R. Goebel, Computational Intelligence: A Logical Approach, 1st edn, Oxford University Press, New York, 1998, pp. 1-2, 9-10.

39 See, e.g., A. Newell \& H.A. Simon, 'GPS, A Program That Simulates Human Thought', in H. Billing (Ed.), Lernende Automaten, Oldenbourg KG, Munich, 1961, reprinted in E.A. Feigenbaum \& J. Feldman (Eds.), Computers and Thought, McGraw-Hill, New York, 1963.

40 Lodder \& Zeleznikow, 2005, pp. 288-289.

41 R.E. Mueller, 'The Leonardo Paradox: Imagining the Ultimately Creative Computer', Leonardo, Vol. 23, No. 4, 1990, p. 427.

42 A. Lodder \& J. Zeleznikow, 'Artificial Intelligence and Online Dispute Resolution', in M.A. Wahab, E. Katsh \& D. Rainey (Eds.), Online Dispute Resolution: Theory and Practice, A Treatise on Technology and Dispute Resolution, Eleven International Publishing, The Hague, 2012, pp. 73, 75.

43 See, e.g., T.A. O'Callaghan, J. Popple \& E. McCreath, 'Building and Testing the SHYSTER-MYCIN Hybrid Legal Expert System', The Australian National University Technical Report, TR-CS-03-01, 2003. Retrieved on 5 May 2015 from <http://papers.ssrn.com/sol3/papers.cfm?abstract_id= 1335658>.

44 Lodder \& Zeleznikow, 2012, p. 75.

45 Lodder \& Zeleznikow, 2005, p. 292.

46 Mountain, 2002, p. 1065. 
reasoning. ${ }^{47}$ Others attempted to provide sophisticated analysis and interpretation of legal rules or to support advanced legal decision-making. ${ }^{48}$ Some sought to represent rule-based analyses of legislation, ${ }^{49}$ while others emulated case-based reasoning by extracting rules from specific cases. ${ }^{50}$ Over time, the widespread adoption of these sophisticated systems proved out of reach. ${ }^{51}$

Reasons for the failure of these earlier successes include the high cost of building sophisticated systems and limited demand for such specialized tools. ${ }^{52}$ It may have also been true that as late as the 1980s, the absence of the always-upto-date Internet made it difficult to provide access to these systems, let alone keep them current. ${ }^{53}$

Widespread adoption may have also been impeded by uncertainty over the appropriate roles for these earlier systems. In the highly aspirational context of the 1980s, discussions around AI justice systems went well beyond the notion of simple, supportive tools, implying they would resemble something closer to human actors. Some early pioneers in the field suggested a need to consider jurisprudential theory in relation to the systems, and to incorporate it into their very designs. ${ }^{54}$ In our current era, it should be easier to accept that AI systems can be practical tools as opposed to autonomous systems that engage legal decisionmaking on advanced or philosophical levels. ${ }^{55}$

\subsection{Making Space for a Simpler System}

Despite the failure to achieve widespread adoption of $\mathrm{AI}$ in the legal realm, explorations in this area should continue. As access to justice problems enter a 'crisis' level, ${ }^{56}$ technology continues to progress. The JPES is meant to be a modest, practical and realistic system for implementation and adoption on a wide scale. If it succeeds, it could help to advance the development of AI justice technologies while also enhancing access to justice and ODR processes.

49 See, e.g. W.G. Popp \& B. Sc a Case', Jurimetrics Journal, Vol. 15, No. 4, 1975, p. 303.

50 See, e.g., J.A. Meldman, 'A Preliminary Study in Computer-Aided Legal Analysis', Massachusetts Institute of Technology Technical Report, 1975. Retrieved on 29 July 2013 from <http://dl.acm.org/ citation. .fm?id=888945> .

51 Schafer, 2010, p. 386.

52 Mountain, 2002, p. 1065.

53 Id., p. 1072.

54 Susskind, 1986, pp. 184-194.

55 Schafer, 2010, p. 386.

56 Canadian Forum on Civil Justice, 'The Cost of Justice: Weighing the Costs of Fair \& Effective Resolution to Legal Problems', Project Background Document, 2012, pp. 1, 4. Retrieved on 30 July 2013 from <www.cfcj-fcjc.org/sites/default/files/docs/2012/CURA_background_doc.pdf>; see also Roach \& Sossin, 2012, p. 1; L.H. Tribe, 'Senior Counselor for Access to Justice, Speech at the National Institute of Justice', Arlington, 14 June 2010. Retrieved on 23 July 2013 from <www.justice.gov/atj/opa/pr/speeches/2010/atj-speech-100614.html〉. 
Shifting the orientation from highly advanced to more modest systems in the legal realm will parallel the evolution of AI generally. ${ }^{57}$ According to technology author and journalist Steven Levy, the failure of initial, highly ambitious AI efforts led to a 'Winter' where no projects or visions could 'grow. ${ }^{\text {.5 }}$ In his view, this Winter was followed by a reorientation towards processes where computers were highly proficient. In Levy's words: “[...] as the traditional dream of AI was freezing over, a new one was being born: machines built to accomplish specific tasks in ways that people never could." ${ }^{2}$ In the justice context, the JPES is consistent with a shift to simpler, less sophisticated, more practical AI products that herald a new Spring, characterized by the delivery and deployment of these systems.

\section{5}

\section{Expert Systems}

This section provides very brief introductions to expert systems generally.

\subsection{Expert System Taxonomy}

In AI terms, the JPES may be characterized as an expert system. Expert systems are domain-specific AI systems that imitate the intelligence experts. ${ }^{60}$ System designers acquire knowledge from human experts and structure it in a technology-based platform. ${ }^{61}$ The resulting systems are then seen to be capable of problem-solving and reasoning. ${ }^{62}$

Expert systems are used in a range of subject areas or knowledge domains, including medicine, mathematics, engineering, chemistry, defence, education, business and law. ${ }^{63}$ Their functions often include problem diagnosis, planning and recommending courses of action. ${ }^{64}$

Some commentators argue that expert systems must have a high level of specialization, and consider less advanced versions to be appropriately called 'knowledge-based' systems. ${ }^{65}$ However, others accept the term expert system can be applied to either type. ${ }^{66}$ For descriptive purposes, the term 'expert system' is used to describe the JPES because, from the perspective of a non-expert user, it provides some level of expertise in the subject domain.

57 S. Levy, 'The AI Revolution Is On', Wired Magazine, 27 December 2010. Retrieved on 25 July 2013 from <www.wired.com/2010/12/ff_ai_essay_airevolution>.

58 Id.

59 Id.

60 Susskind, 1986, p. 172.

61 G.F. Luger \& C. Chakrabarti, 'Knowledge-Based Probabilistic Reasoning From Expert Systems to Graphical Models', University of New Mexico Technical Report, TR-CS-2009-10, 2009, p. 1. Retrieved on 5 May 2015 from <www.cs.unm.edu/ treport/tr/09-11/luger.pdf〉.

62 Susskind, 1986, p. 172.

63 Luger \& Chakrabarti, 2009, p. 1.

64 R.S. Engelmore \& E. Feigenbaum, 'Introduction', in R.S. Engelmore (Ed.), Knowledge-Based Systems in Japan, Loyola College, Maryland, JTEC, 1993. Retrieved on 28 July 2013 from <www. wtec.org/loyola/kb/c1_s1.htm>.

65 Lodder \& Zeleznikow, 2005, p. 293.

66 Engelmore \& Feigenbaum, 1993. 


\subsection{Basic Expert System Architecture}

The basic structural components of an expert system are the knowledge base, inference engine and user interface. ${ }^{67}$

The knowledge base is the core of the system where domain-specific expert knowledge is stored. ${ }^{68}$ Expert content is structured in the knowledge base in the form of production rules. ${ }^{69}$ In general terms, a production is a condition, followed by an action, used to define a step in the reasoning process. ${ }^{70}$ The antecedent part of the rule is factual or 'real-world' in nature. The consequent part expresses the application of the rule to that condition once it is satisfied ${ }^{71}$ or asserted to be 'true'. ${ }^{72}$ The condition-action formulation permits the system to reason deductively, by way of conditional 'if...then...' statements ${ }^{73}$ written in the English language. ${ }^{74}$ In this formulation, the 'if...' represents the condition, while the 'then...' determines the action to be taken, resulting in 'if (condition), then (action)' statements. ${ }^{75}$ This form of rule is naturally suited to represent human problem-solving approaches. ${ }^{76}$

The inference engine is the module that manipulates and interacts with the knowledge base to perform the system's reasoning. ${ }^{77}$ When the condition of a rule is satisfied, it 'fires' or executes a specific action. ${ }^{78}$ This action often involves setting a subsequent production rule into action. ${ }^{79}$ The inference engine thus interacts with the production rules, which form the structure of the knowledge base.

Humans interact with the system through its user interface. ${ }^{80}$ This part of the expert system translates user inputs into a format that can be understood and computed by a computer. In turn, it also translates outputs into a format the user can understand. ${ }^{81}$

67 References to other components including the working memory and knowledge acquisition module are omitted for lack of applicability to the JPES conceptual description.

68 L.Y. Shue, C.W. Chen \& C.H. Hsueh, 'An Ontology-Based Expert System for Financial Statements Analysis', in A. Eardley \& L. Uden (Eds.), Innovative Knowledge Management: Concepts for Organizational Creativity and Collaborative Design, IGI Global, New York, 2010, pp. 125, 138.

69 Engelmore \& Feigenbaum, 1993.

70 Luger \& Chakrabarti, 2009, p. 3.

71 Id.

72 Id., p. 4.

73 M. Aikenhead, 'Legal Knowledge-Based Systems: Some Observations on the Future', Web Journal of Current Legal Issues, Vol. 2, 1995. Retrieved on 2 January 2013 from <http://webjcli.ncl.ac.uk/ articles2/aiken2.html>.

74 M.C. Lovett \& J.R. Anderson, 'Thinking as a Production System', in K. Holyoak \& R. Morrison (Eds.), The Cambridge Handbook of Thinking and Reasoning, Cambridge University Press, New York, 2005, p. 401. Id. Luger \& Chakrabarti, 2009, p. 2.

Engelmore \& Feigenbaum, 1993.

Lovett \& Anderson, 2005, p. 402.

Id.

M.L. Maher \& P. Longinos, 'Development of an Expert System Shell for Engineering Design', Carnegie Mellon University Technical Report, Department of Civil and Environmental Engineering, 1986, p. 9. 
Expert systems can exist as 'shells' or skeletons that contain the inference engine and user interface, but none of the domain-specific expert knowledge. ${ }^{82}$ These systems can be purchased commercially, ${ }^{83}$ from the smallest, single PCsized versions to large mainframe systems. ${ }^{84}$

However, as Edward Feigenbaum has noted, the performance of an AI system depends not on the technology used, but on the knowledge that is programmed into it. ${ }^{85}$ In his words:

[Knowledge acquisition] is the most important of the central problems in artificial intelligence research. The reason is simple: to enhance the performance of AI's programs, knowledge is power. The power does not reside in the inference procedure. The power resides in the specific knowledge of the problem domain. ${ }^{86}$

Accordingly, much of this article will focus on the functional aspects of the JPES and on the processes that relate to constructing the knowledge base, as opposed to generic expert system technologies. ${ }^{87}$

This section describes the JPES, and includes brief examples to illustrate its functions. The description begins by outlining the system's goals.

\subsection{Goals}

A primary JPES goal is to draw on expert knowledge and AI to support users dealing with common issues and dispute types. System functions include problem diagnosis, information, self-help tools and streaming or triage (see Figure 1). In the interests of usability, attention is also given to the presentation of expert knowledge and to the way users interact with the system.

From a user's perspective, the JPES will provide guidance, first on how to manage disputes independently, and second, on how to engage with various justice system processes. In some instances, the system may help users obtain selfdirected resolutions of their disputes.

From the system administrator's perspective, the JPES should provide its guidance in a way that is accessible, efficient and affordable. In terms of managing expectations, the goal is not to meet every need of every user through the entire justice process, because this is unattainable with a relatively simple AI

82 Engelmore \& Feigenbaum, 1993.

83 See, e.g., Maher \& Longinos, 1986, p. 9.

84 Engelmore \& Feigenbaum, 1993.

85 E. Feigenbaum, 'Knowledge Engineering: The Applied Side of Artificial Intelligence', Annals of the New York Academy of Sciences, Vol. 426, 1984, pp. 91, 92.

86 Id., p. 92.

87 Exploration of expert system technology, including commercially available systems, is beyond the scope of this paper. The interested reader is invited to consult Engelmore \& Feigenbaum, 1993, available from <www.wtec.org/loyola/kb/c1_s4.htm>. 
approach. But it should provide some guidance and support, while also avoiding the intensification of access to justice problems for users. ${ }^{88}$

In the Netherlands, the Dutch Legal Aid Board and the InnoJustice Lab have created a system that includes some of the features and functions described here. The Web-based Rechtwijzer ${ }^{89}$ uses an intelligent questionnaire format, and provides problem diagnosis, triage, information, guidance and self-help tools for non-lawyer users. ${ }^{90}$

Like the Rechtwijzer, the JPES emphasizes usability and avoids overly sophisticated AI technology. ${ }^{91}$ These systems do not 'do the thinking for users', but instead provide support and guidance with an expectation that users will exercise their own discretion over how to act on these outputs. ${ }^{92}$

\section{Figure 1}

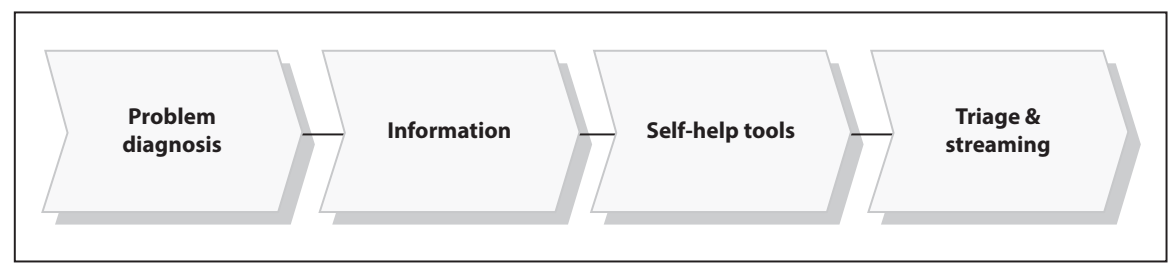

JPES Functions

\subsection{The JPES AI Approach}

Users engage the JPES through an 'intelligent questionnaire' interface. Each question is accompanied by a defined set of answers corresponding with the system's production rules. Questions are presented individually, allowing for step-by-step advancement down knowledge 'pathways'. Each of these functions is described in the following sections.

Expert knowledge, including legal and non-legal information, is translated into a non-traditional visual format. Rather than written case summaries or procedural guidebooks, the user interface provides information through the intelligent questionnaire format. In addition to text, information can also be provided in dynamic formats such as video. Through non-textual methods of communica-

89 See Rechtwijzer, available from <www.rechtwijzer.nl/> (site offered in Dutch only).

90 Hague Institute for the Internationalisation of Law, 'Signpost to Justice: Guidance for Citizens Facing Justiciable Problems'. Available from <https://web.archive.org/web/20130313190505/ http://www.hiil.org/project/signpost-to-justice-guidance-for-citizens-facing-justiciableproblems $>$.

91 Id.

92 J.V. Veenen, 'Online Integrative Negotiation Tools for the Dutch Council for Legal Aid', Proceedings of the 5th International Workshop on Online Dispute Resolution (ODR Workshop '08), Firenze, Italy, 2008, pp. 23, 24. Retrieved on 19 April 2013 from <http://ssrn.com/abstract=1511704>. 
tion, the JPES can leverage multiple formats and multisensory presentation styles that tend to be underutilized in the justice realm (see Figure 2). ${ }^{93}$

\section{Figure 2}

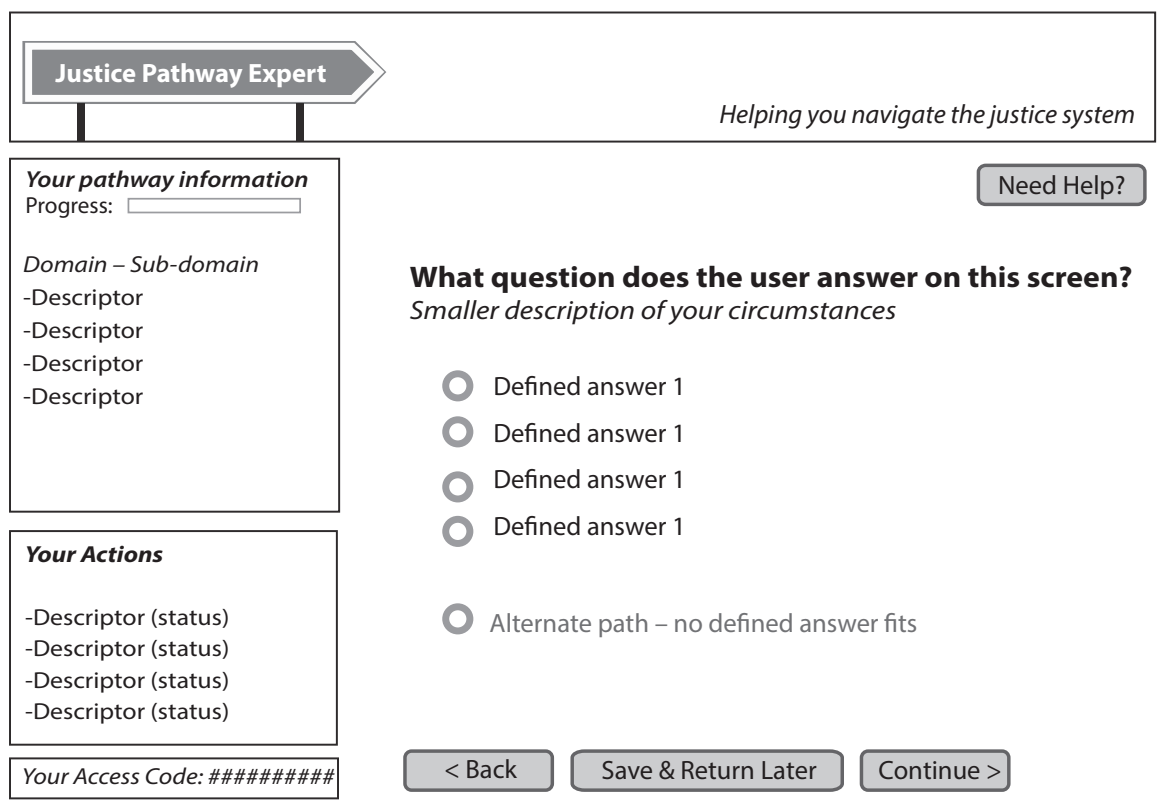

JPES Screenshot - Generic Intelligent Questionnaire

The system's intelligence is revealed when the user's answers or inputs determine the outputs drawn from the knowledge base. In other words, an answer to one question prompts the system to take the next appropriate step. Expressed in production rules, an answer to a question causes a specific production rule to fire, bringing up a subsequent action.

For example, our young college student might be asked to identify her type of problem or dispute, corresponding to a specific subdomain within the knowledge base (see Figure 3).

The JPES screenshot shows that the user selected the 'loan or debt' condition to reflect her circumstances. Her selection of this 'condition' causes that specific production rule to fire, prompting a corresponding 'action'.

The inference engine then displays a subsequent question on the loan and debt pathway, shown in Figure 4.

93 See, e.g., C.R. Brunschwig, 'Law Is Not or Must Not Be Just Verbal and Visual in the 21st Century: Toward Multisensory Law', in D.J. Svantesson \& S. Greenstein (Eds.), Nordic Yearbook of Law and Informatics 2010-2012: Internationalisation of Law in the Digital Information Society, ExTuto Publishing, Copenhagen, 2012, p. 231. 


\section{Figure 3}

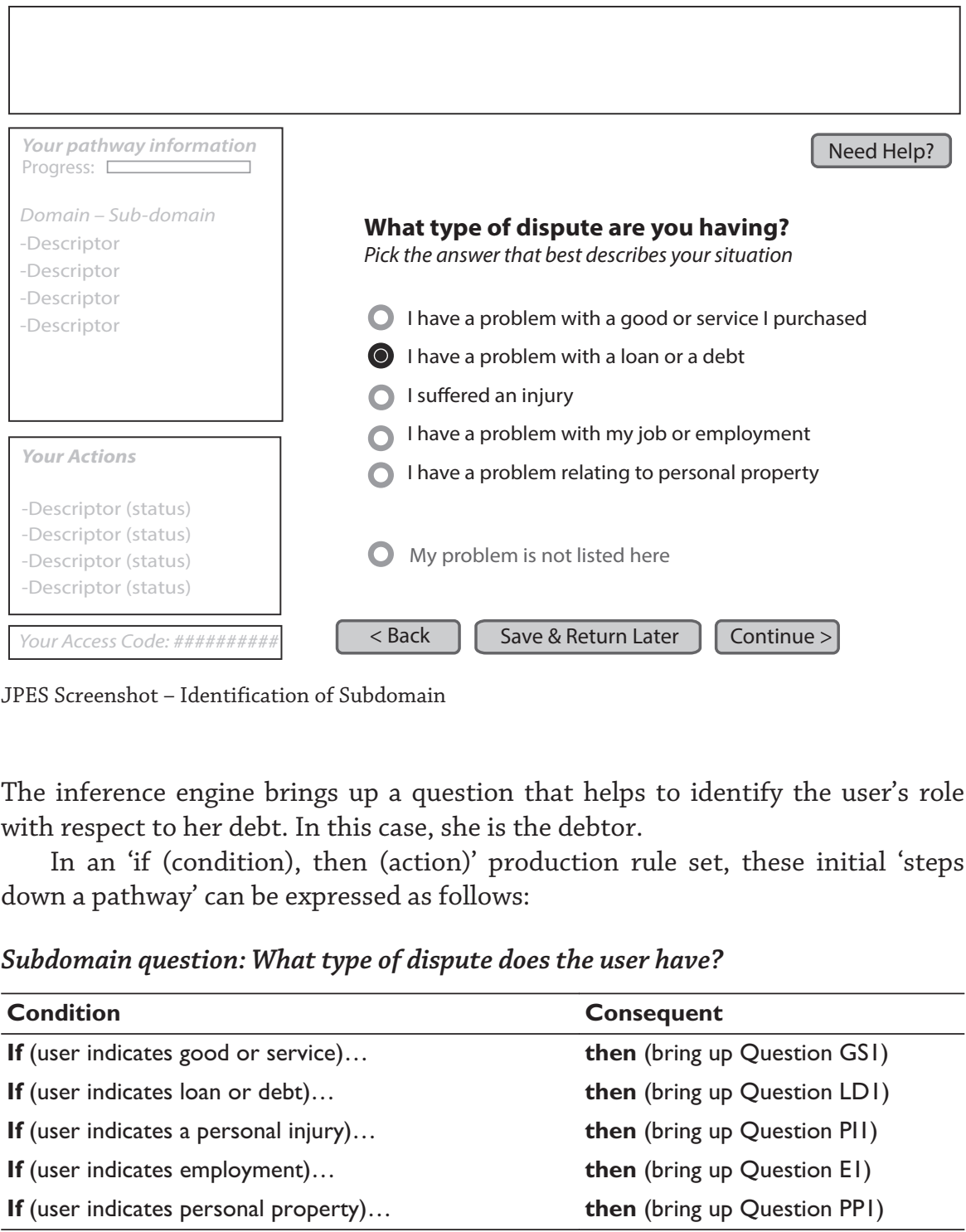




\section{Figure 4}

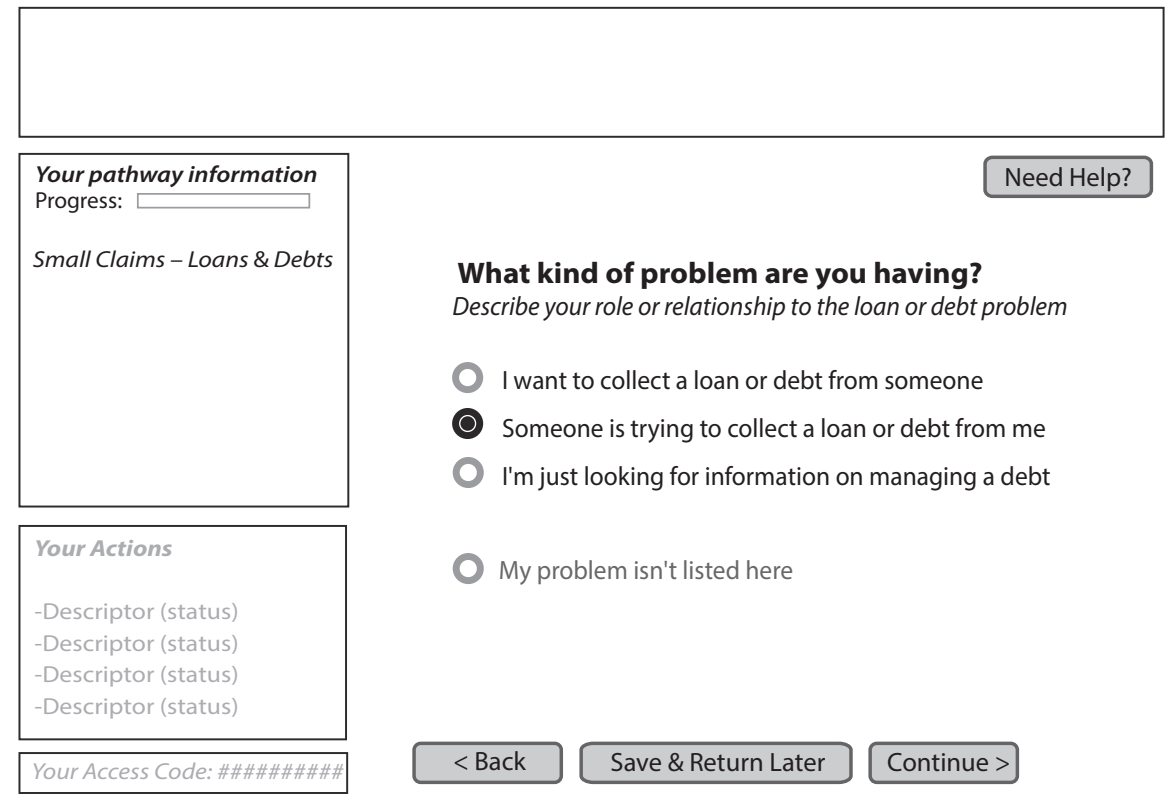

JPES Screenshot - Loan and Debt - Identifying User’s Role

In our example, the user indicates a loan or debt dispute, causing the system to fire the production rule that brings up the first loan and debt question, nominally - LD1. In our example, LD1 attempts to discover whether the user is a creditor, a debtor or someone looking for information on how to manage debts. This question and its corresponding rules can be expressed as:

\section{Question LD1: What kind of problem is the user having?}

\begin{tabular}{ll}
\hline Condition & Consequent \\
\hline If (user indicates [s] he is creditor/collector)... & then (bring up Question LD2) \\
If (user indicates [s] he is debtor)... & then (bring up Question LD3) \\
If (user indicates [s] he is looking for info)... & then (bring up Question LD4) \\
If (user indicates problem not listed)... & then (bring up Question LD5) \\
\hline
\end{tabular}

Question LD2 would be a second step down the loan and debt pathway.

Questions may contain an answer or option to indicate that the user's particular 'condition' is not one of the defined answers. In these situations, the JPES can display additional explanatory information to reduce the likelihood the question was simply misunderstood, after which time the original question is displayed again. Beyond that, the system could provide an online form to let users describe their circumstances in natural language that is then sent to system administrators for manual review. If the knowledge base is found to be missing a production 
rule, it could then be added on the basis of this feedback. Depending on available resources, live support by Internet chat or email could also be used in these situations.

In some systems, production rules are linked together, allowing the inference engine to consider one rule, draw a conclusion and then apply it to a further reasoning process according to the next rule. ${ }^{94}$ This forward-chaining approach stores multiple facts or conditions entered by the user in its working memory, which are then used to search for corresponding matches in the knowledge base. ${ }^{95}$ In these systems, a series of deductions can be set in motion from a single input, all leading to a particular conclusion or recommendation. ${ }^{96}$

In contrast, the JPES presents each question and its defined answers individually. By this approach, the JPES addresses larger problems in discrete sub-components, only taking a step towards the ultimate conclusion or recommendation as each rule is satisfied or asserted to be true for the user's specific circumstances. ${ }^{97}$ This approach opts for simplicity over complexity, even at the risk of creating more steps.

Breaking the reasoning process into individual steps mitigates challenges in the legal domain relating to the 'open texture' of legal concepts. ${ }^{98}$ Deconstructing multifaceted issues into discrete questions reduces pressure on the system to interpret context from situations with multiple facts ${ }^{99}$ or to accommodate variances in language that may be used to describe a situation. The step-by-step approach also mitigates the inherent AI weakness created by its lack of 'common sense' relating to context. ${ }^{100}$

The step-by-step approach does not completely eliminate context or open texture from the reasoning process. Production rules represent a formalized version of problem-solving heuristics ${ }^{101}$ applied to the justice domain. But this heuristic knowledge is not meant to represent perfect logic; good judgment, practice and plausibility are accepted elements of the problem domain. ${ }^{102}$ The individual question approach merely affords greater control over the reasoning process by forcing these elements into a deductive structure. If they are made available in pathways, users will decide how they apply to their specific circumstances.

94 A. Oskamp \& A.R. Lodder, 'Introduction: Law, Information, Technology and Artificial Intelligence', in A.R. Lodder \& A. Oskamp (Eds.), Information Technology and Lawyers, Springer Publishing, The Netherlands, 2006, pp. 1, 5.

95 Luger \& Chakrabarti, 2009, p. 4.

96 R. Bogacz \& C. Giraud-Carrier, 'Learning Meta-Rules of Selection in Expert Systems', Proceedings of the Fourth World Congress on Expert Systems, 1998, p. 576. Retrieved on 10 August 2013 from <www.cs.bris.ac.uk/Publications/Papers/1000256.pdf〉.

97 Luger \& Chakrabarti, 2009, p. 5.

98 J. Franklin, 'Discussion Paper: How Much of Commonsense and Legal Reasoning Is Formalizable? A Review of Conceptual Obstacles', Law, Probability and Risk, Vol. 11, No. 2, 2012, pp. 225, 226-230.

99 Id., pp. 231-233.

100 Popple, 1996, p. 104.

101 Lovett \& Anderson, 2005, p. 407.

102 Engelmore \& Feigenbaum, 1993. 
As a deductive reasoning system, the JPES differs from case-based AI models in the legal domain ${ }^{103}$ that search for relevant similarities (or differences) among cases. ${ }^{104}$ These systems rely on various approaches including semantic analyses ${ }^{105}$ or other algorithms to model various 'factors' within cases, which are then weighed and compared. ${ }^{106}$ Again, the JPES avoids this approach in favour of simplicity and better understandability for users.

If necessary, the JPES's deductive rules could emulate a case-based approach. For example, the system could ask a user to identify whether certain facts or circumstances summarized from a potentially relevant case apply to their situation. In our loan and debt example, a case-based question may take the following form (see Figure 5).

\section{Figure 5}

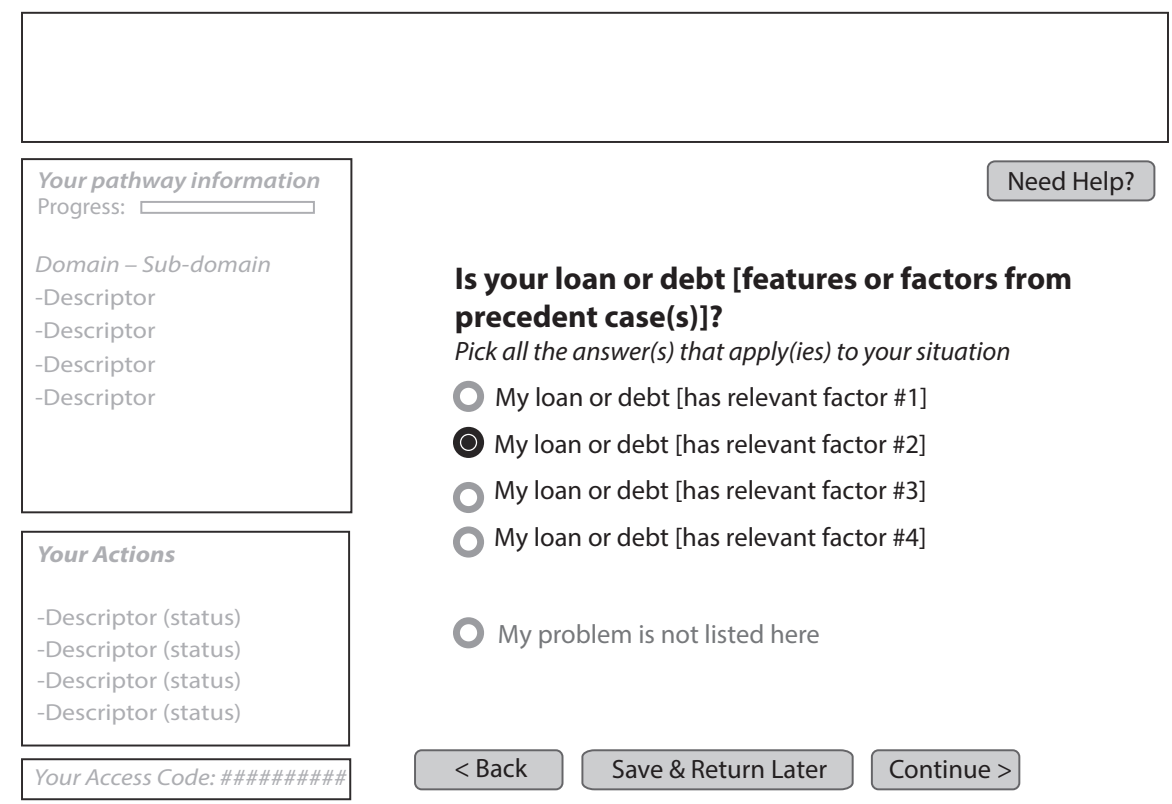

JPES Screenshot - Case-Based Reasoning in Deductive Rule Format

When the user indicates that relevant facts or circumstances from the precedent case apply to their situation, the inference engine presents subsequent questions

103 Popple, 1996, pp. 40-44.

104 K.D. Ashley, 'Toward a Computational Theory of Arguing with Precedents: Accommodating Multiple Interpretations of Cases', Proceedings of the 2nd International Conference on Artificial Intelligence and Law, ACM Press, New York 1989, p. 93.

105 See GREBE system, as described in L.K. Branting, 'Representing and Reusing Explanations of Legal Precedents', Proceedings of the 2nd International Conference on Artificial Intelligence and Law, ACM Press, New York, 1989, pp. 103, 105-110.

106 See Ashley, 1989. 
or production rules. In the screenshot above, the user selected 'relevant factor \#2', prompting a question to test for additional factors and a more specific comparison with the precedent under consideration (see Figure 6).

\section{Figure 6}

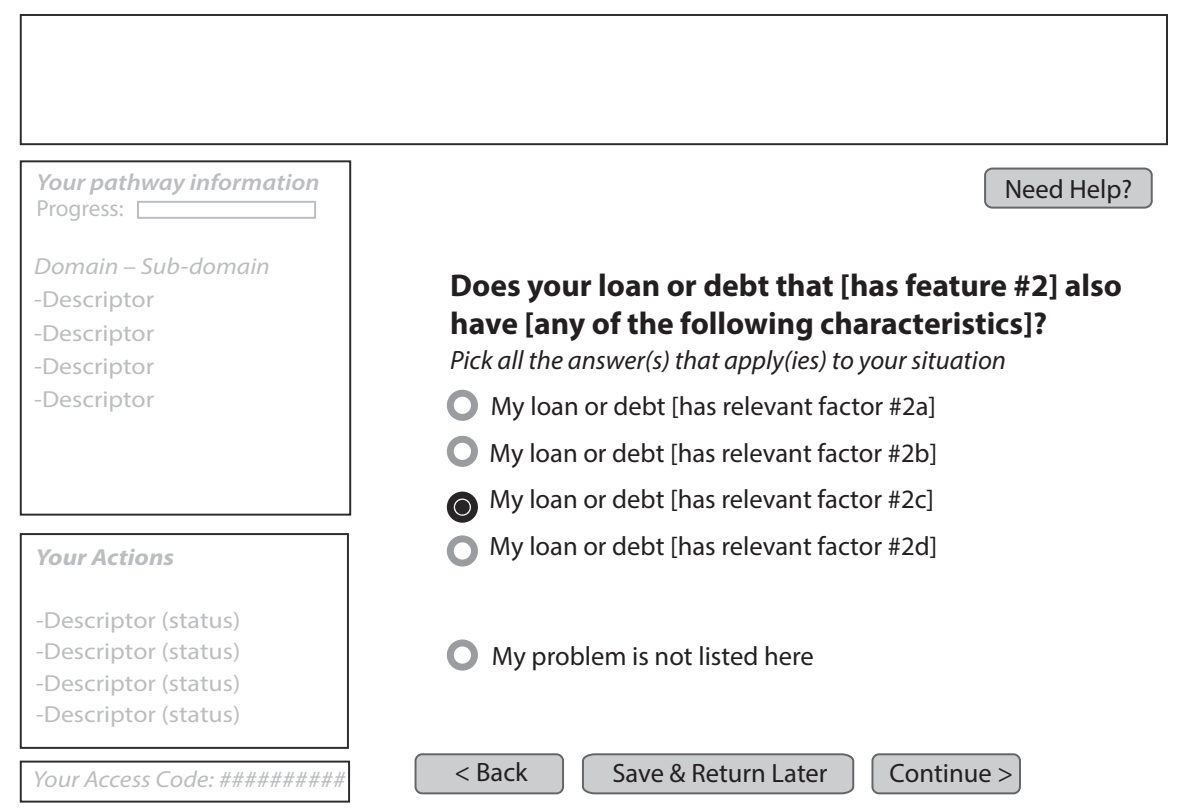

JPES Screenshot - 2nd Level Case-Based Emulation

The production rules could be as specific as necessary to identify the appropriate case.

Attempts to emulate this type of case-based reasoning would add to the system's complexity. It may also be of limited benefit to non-expert users who seek less legalistic and more practical forms of guidance in the early stages of their dispute. ${ }^{107}$ This discussion is therefore offered only to acknowledge this capacity of the JPES.

The following sections describe how the JPES accomplishes its stated goal to support users with its problem diagnosis, information, self-help tools and streaming and triage functions.

\subsection{Problem Diagnosis}

Problem diagnosis is an important first step in the pathway. First, this function helps the user recognize the nature of their problem or dispute. Second, it identifies the beginning of the appropriate pathway through the knowledge base. 
In many cases, users will not fully understand the type of problem they are facing, or the issues involved. ${ }^{108}$ The intelligent questionnaire interface helps diagnose the problems or issue types and prepares users for subsequent steps.

Problem diagnosis also identifies the appropriate domain or subdomain within the knowledge base. Following on the examples presented above, a first step helped our user diagnose her problem as one in the loan and debt subdomain of the larger civil or small claims domain (JPES Screenshot - Identification of Subdomain). The user then identified herself as a debtor (JPES Screenshot - Loan and Debt - Identifying User's Role). Further diagnosis production rules are used to determine the user has a debt she does not wish to dispute, as demonstrated in Figure 7.

\section{Figure 7}

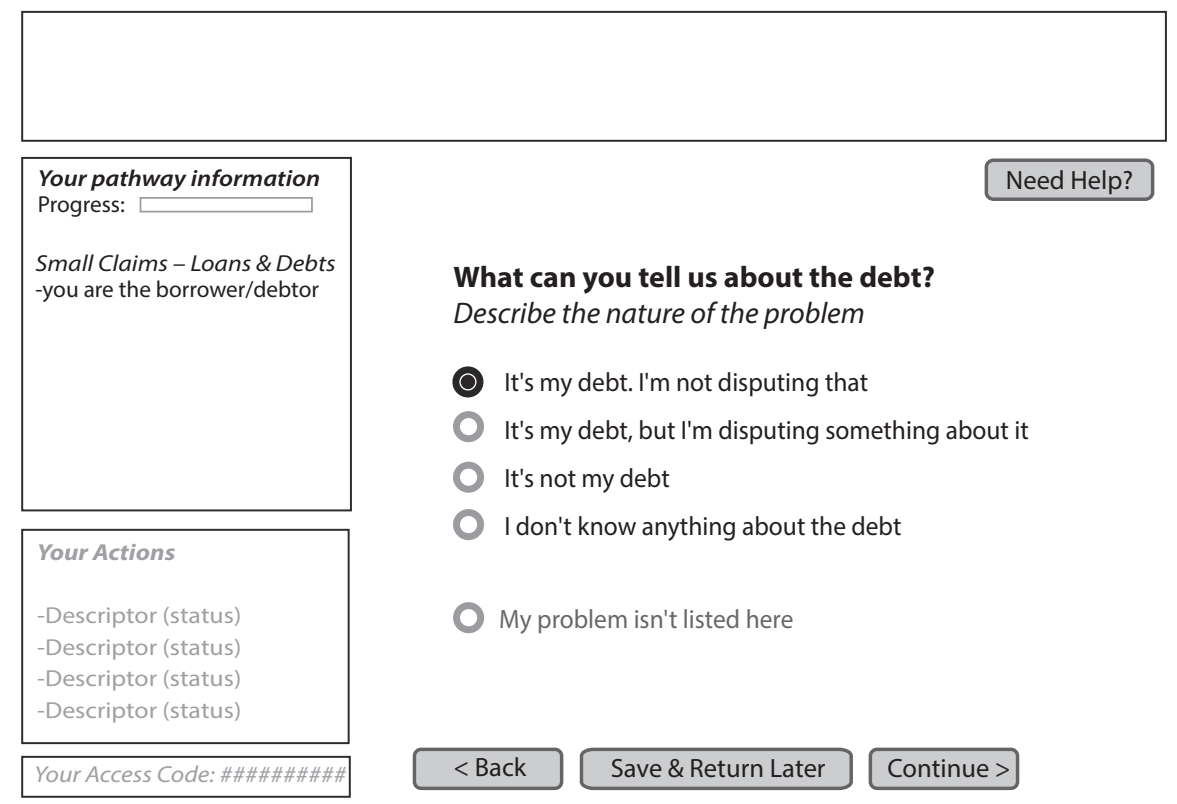

JPES Screenshot - Identifying Type of Loan and Debt Problem

108 See Cabral et al., 2012, at p. 293, n. 306. In n. 306, the authors argue that, "Often, litigants and potential litigants do not have a full or accurate understanding of the type of legal problem they face. It is critical that the questions be developed so they are responsive to the ways that litigants understand the issues. For example, rather than asking 'Do you have a governmental child support case?' or 'Is your case handled by a Title IV-D agency?' the system might ask, 'Have you been to 455 McAllister?' (perhaps with a picture of the agency in question)." 
Subsequently, the production rules determine the creditor has not begun a collections process with respect to the debt (which would bring up a specific legislative regime in B.C. ${ }^{109}$ ) (see Figure 8 ).

\section{Figure 8}

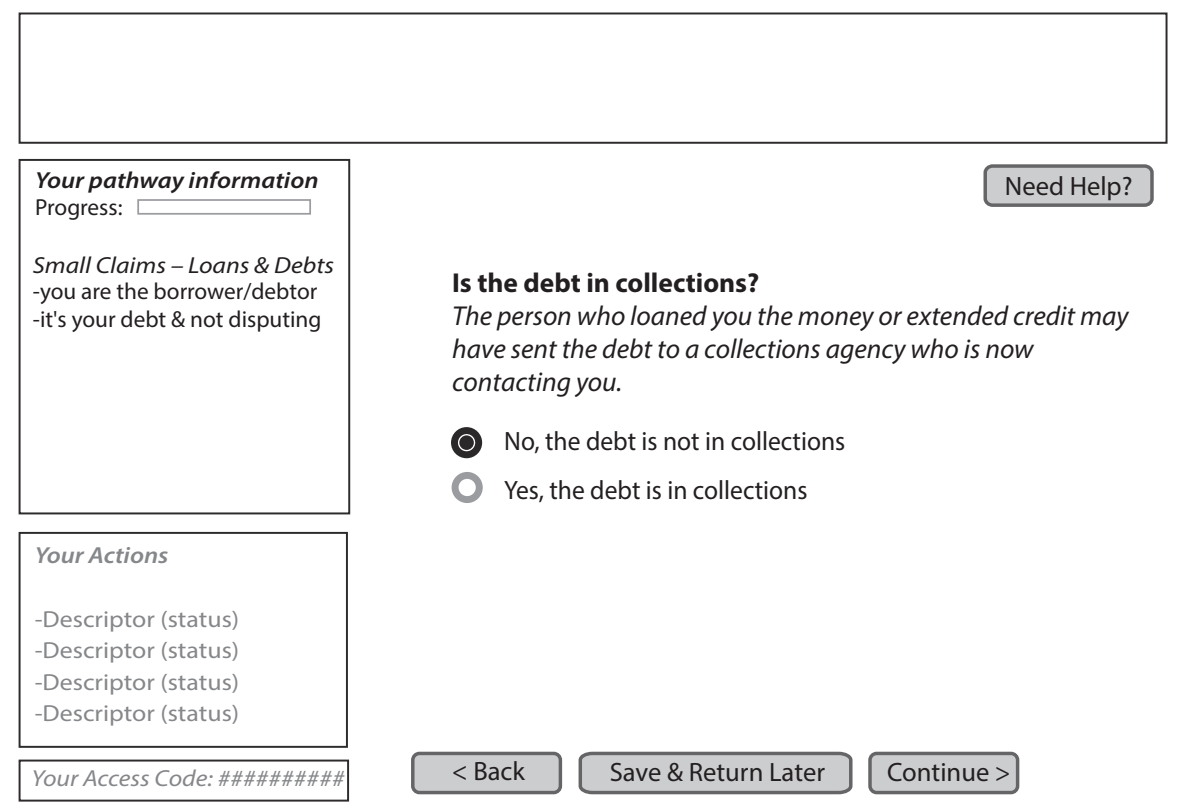

JPES Screenshot - Identifying Whether Loan or Debt in Collections

A further question confirms that the user is having difficulties making repayments (see Figure 9).

While this functionality may seem elementary to experts, it could be very beneficial for inexperienced users. More importantly, this process causes the inference engine to fire production rules that move along the loan and debt pathway and prepare the user for subsequent functions (see Figure 10).

Rather than create a system to address every conceivable aspect of every type of dispute, the problem diagnosis function's scope is limited to the JPES's knowledge domain, and to the level of detail necessary to achieve the system's objectives.

\subsection{Information}

Once a user's problem is diagnosed, the system can deliver specific information. For the JPES, the goal is to provide the type of information that would come from

109 See the B.C. Business Practices and Consumer Protection Act, SBC, 2004, Chapter 2, Part 7 on 'Debt Collection'. Retrieved on 5 May 2015 from <www.bclaws.ca/Recon/document/ID/freeside/ 04002_00>. 


\section{Figure 9}

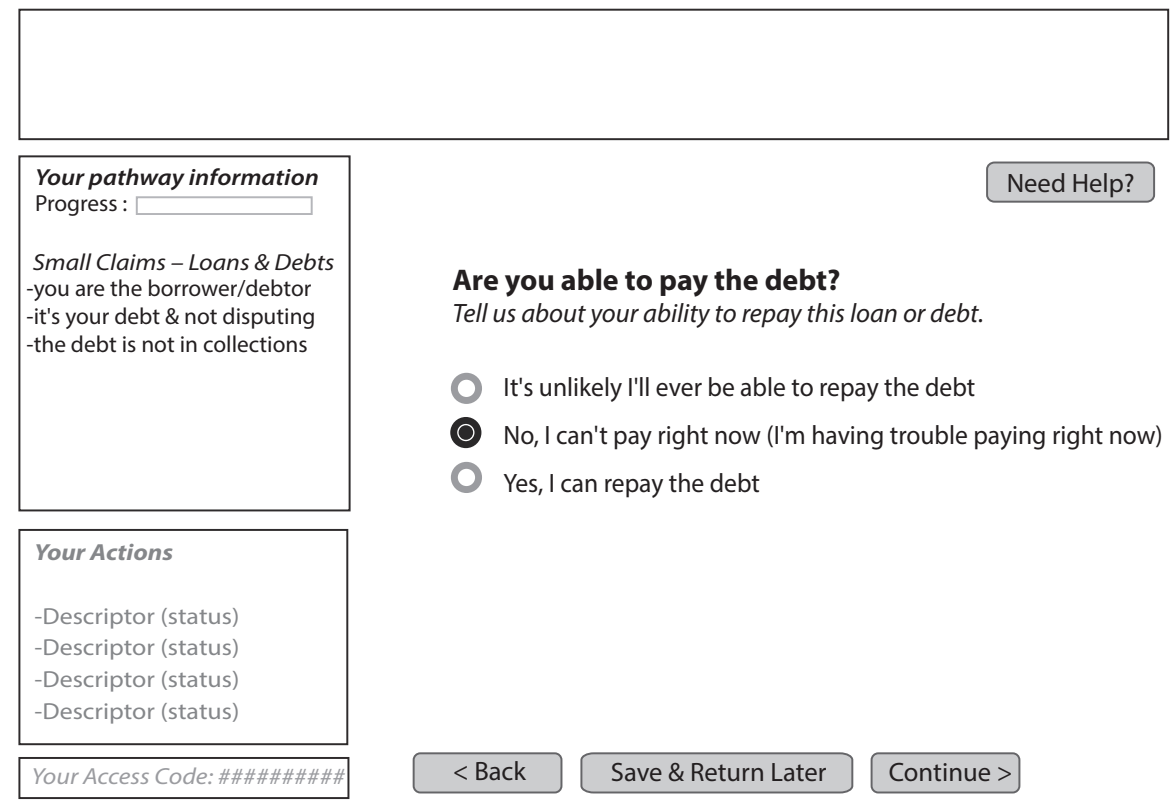

JPES Screenshot - User's Ability to Repay

human experts. Aside from the obvious benefits of making the user more informed about the problem, evidence suggests dispute resolution processes work more efficiently when information is provided at an early stage. ${ }^{110}$

Information may also be provided to help the user understand the questions being asked in conjunction with the relevant production rules. In our loan and debt example, the system could provide the following information to help our user understand the question of whether her debt is in collections (see Figure 11).

The information function can deliver different types of expert information ranging from relatively formal, legalistic content to non-legalistic or 'real-world' guidance. ${ }^{111}$ Specific legal information could include plain language interpretations of policies or legislation relevant to the particular dispute. Less legalistic dispute resolution information could include descriptions of commonly negotiated outcomes for specific dispute types. Very practical information might include a video explaining 'how to have a difficult conversation' with another person.

From a practical perspective, significant benefits may be gained by helping users appreciate what shape a reasonable outcome or resolution may take for spe-

110 McHale, 2012, p. 367.

111 Mommers et al., 'Understanding the Law: Improving Legal Knowledge Dissemination by Translating the Contents of Formal Sources of Law', Artificial Intelligence and Law, Vol. 17, No. 1, 2009, pp. 51, 56. 


\section{Figure 10}

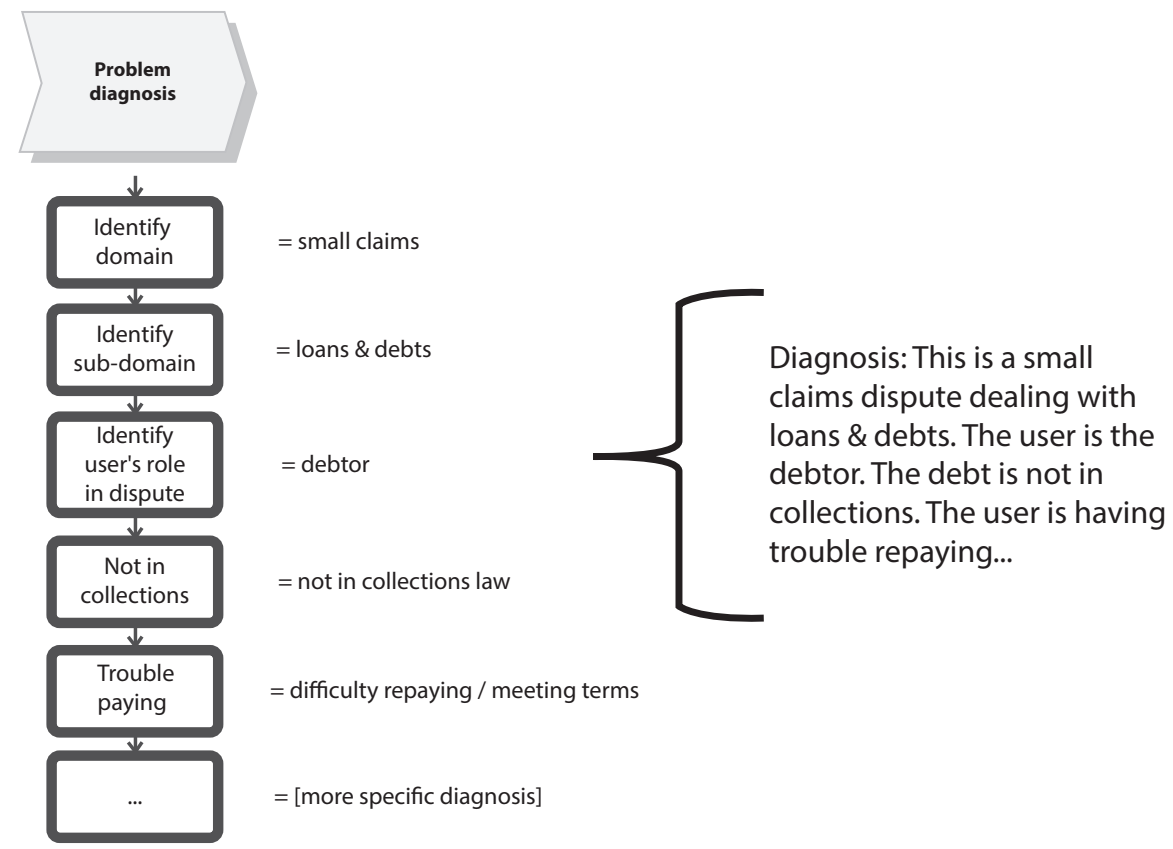

Functional Overview - Problem Diagnosis

cific dispute types. ${ }^{112}$ Some of this information could also shape the user's expectations by providing information about the expected length, cost and effort of the process, along with steps that may be taken.

In a negotiation support context, JPES informational functions could be constructed to help the user identify interests or issues in the dispute that could then be analysed and evaluated. ${ }^{113}$ Other information could help the user estimate chances of 'success' in terms of a win/lose projection if the dispute were to be adjudicated, or provide information to help formulate a best alternative to a negotiated agreement (BATNA). ${ }^{114}$ This information could include statistical summaries of outcomes in court or tribunal adjudications for the user's case type. Initially, we should expect such predictions to be relatively basic; in the future, these ODR functions are likely to become more accurate than human experts. ${ }^{115}$

112 J.V. Veenen, 'From :-( to :-) Using Online Communication to Improve Dispute Resolution', TISCO Working Paper Civil Law and Conflict Resolution Systems, No. 002/2010, 2010, p. 33. Retrieved on 2 January 2013 from <http://ssrn.com/abstract=1618719>.

113 Lodder \& Zeleznikow, 2005, pp. 310-312.

114 Id., p. 301.

115 D.M. Katz, 'Quantitative Legal Prediction - or - How I Learned to Stop Worrying and Start Preparing for the Data Driven Future of the Legal Services Industry', Emory Law Journal, Vol. 62, 2012, pp. 909, 928-929. 


\section{Figure 11}

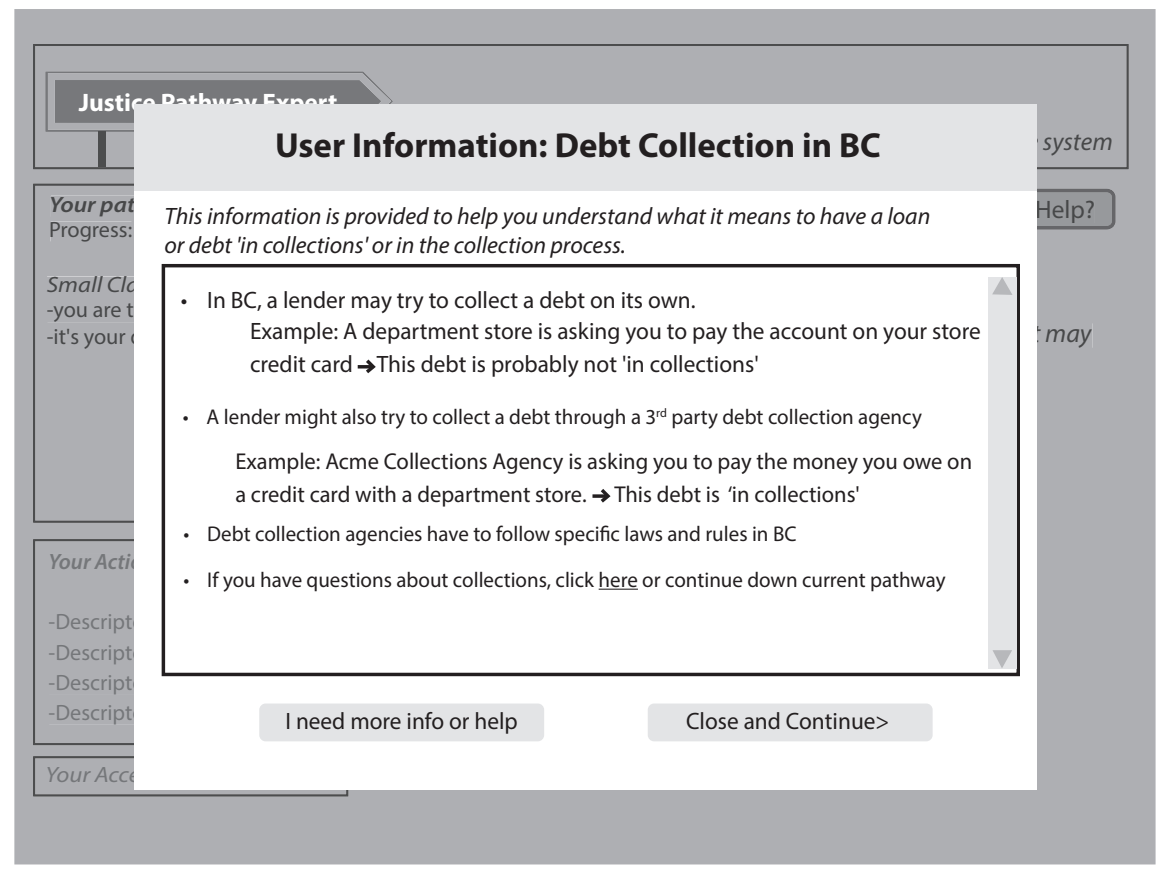

JPES Screenshot - Information on Collections

The information provided should support users on their specific pathways into the justice system or to a resolution. It should be distinguished from broader educational and procedural information about justice system processes. Providing too much information, especially of a legalistic nature, can quickly overwhelm users. ${ }^{116}$ Accordingly, the amount of information should be kept to a minimum and be practically oriented to the user's situation (see Figure 12). ${ }^{117}$

Guiding users down specific pathways and providing targeted information could create concerns that the JPES goes beyond information and provides legal advice ${ }^{118}$ or engages in the unauthorized practice of law. As Linda Rexer and Phil Malone observe, there is a good deal of uncertainty in the justice sector over the precise difference between information and advice, making it difficult to determine what is and is not appropriate. ${ }^{119}$ Many definitions infer that information becomes advice when it is tailored to a user's specific circumstances, which suggests the JPES could be at risk. ${ }^{120}$ From a practical standpoint, well-meaning court registry staff and non-profit public information providers struggle to bal-

116 Mommers et al., 2009, p. 52.

117 Macfarlane, 2013, p. 64.

118 Cabral et al., 2012, p. 318.

$119 \mathrm{Id}$.

$120 \mathrm{Id}$ 
Figure 12
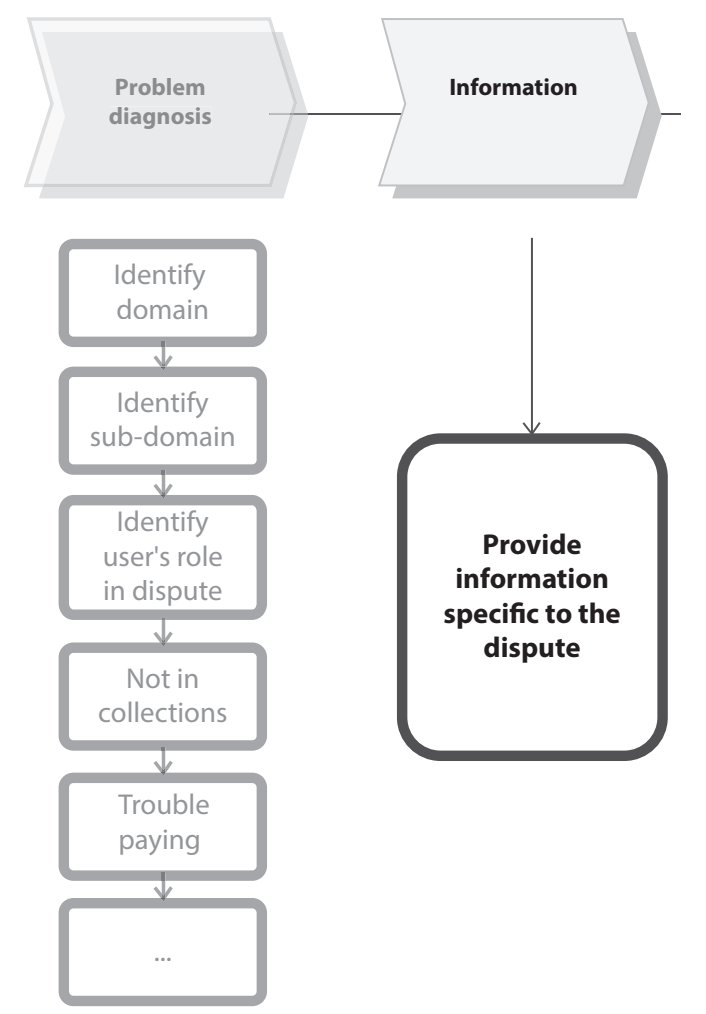

Functional Overview - Information

ance tensions between legal information and advice on a daily basis. ${ }^{121}$ The evidence shows they consistently try to help users despite believing that their own policies for making the distinction are either imprecise or non-existent. ${ }^{122}$

Despite concerns in this area, the JPES specific information approach must be maintained. This assertion is supported by recognizing that overcautious approaches perpetuate the vacuum of information facing inexperienced justice system users. Moreover, it is questionable whether software-based systems can even cross the line into the unauthorized practice of law at all. ${ }^{123}$ Specific information can also be carefully scrutinized by as many professionals as necessary before it is programmed into the JPES. Delivery through a software platform will actually help resolve inconsistencies that occur frequently with humans. ${ }^{124}$ 
If necessary, these systems could be insulated from the risk of unauthorized practice of law by way of regulatory measures. ${ }^{125}$ Underlying policy reasons include the general level of need for affordable assistance to users, and a desire to avoid stifling future innovations in this area. ${ }^{126}$ It might also be supported by evidence suggesting lawyers only represent $15 \%$ of demand for legal services to the public in any event. ${ }^{127}$

Legislation or regulation could also be used to protect information disclosed to the system from later being produced in adjudicative processes or being discovered through freedom of information requests. Regulatory measures applying comprehensive confidentiality and non-compellability ${ }^{128}$ protections as well as exemption from certain freedom of information legislative provisions ${ }^{129}$ would each be prudent safeguards in this area.

Intelligent questionnaire systems that deliver personalized information and advice have already been deployed in the justice context. For example, the United Kingdom's Department of Work and Pensions has implemented the Sorting Out Separation ${ }^{130}$ tool to provide customized information for separating parents. ${ }^{131}$ The Rechtwijzer ${ }^{132}$ system also provides tailored information, guidance and dispute resolution options for a variety of dispute types. ${ }^{133}$ The JPES is an extension of existing contributions in this area.

\subsection{Self-Help Tools}

In conjunction with its information functions, the JPES provides action-oriented tools. These tools would help users to manage their disputes as they move into the formal justice system, or, potentially, to facilitate early resolutions.

By their nature, self-help tools perform tasks or support decision-making processes without the need of a human expert. As noted by Julie Macfarlane, the 'do-it-yourself' trend is an increasing phenomenon, no doubt influenced by the

125 Cabral et al., 2012, p. 321.

126 Id., p. 322.

127 K. Covert, 'The Client-Driven Revolution', National Magazine, Canadian Bar Association, JulyAugust 2013. Retrieved on 26 July 2013 from <http://stage-na.cba.org/Articles/Recent4/Theclient-driven-revolution.aspx>.

128 See, e.g., the B.C. Small Claims Rules 7.4 (44)-(46) on 'Confidentiality and Compellability for Mediation Information'. Retrieved on 5 May 2015 from <www.bclaws.ca/Recon/document/ID/ freeside/261_93_00b>.

129 See, e.g., the B.C. Civil Resolution Tribunal Act (3rd Reading), 2011, Part 9, Section 89, on 'Confidentiality of Online and Facilitated Dispute Resolution Information'. Retrieved on 5 May 2015 from <www.leg.bc.ca/39th4th/3rd_read/gov44-3.htm\#section89>.

130 See Sorting out Separation, 'Homepage'. Retrieved on 28 July 2013 from <www. sortingoutseparation.org.uk/en/hub.aspx>. The interested reader is directed to the United Kingdom Department for Work \& Pensions, 'Help for Separating Parents at Their Fingertips as New Web App Launches. A Third of Children Now Live in Separated Families', Press Release, 29 November 2012. Retrieved on 27 July 2013 from <www.gov.uk/government/news/help-forseparating-parents-at-their-fingertips-as-new-web-app-launches-a-third-of-children-now-live-inseparated-families $>$.

131 Id.

132 See Rechtwijzer, supra note 89.

133 Veenen, 2010, p. 24. 
Internet. ${ }^{134}$ She suggests this trend could bring 'disintermediation'135 to the justice system if it cuts out lawyers and other professional advisers as the 'middle men.' Richard Susskind, who has also written about disintermediation of legal services, adds that computerized services may soon replace the role of lawyers, in some but not all matters. ${ }^{136}$

On an elementary level, tools could be as simple as videos telling users how to address issues relevant to their disputes. A recent study in Canada suggests some users find videos particularly helpful in the justice context. ${ }^{137}$ One example of a video already in use by the Justice Education Society of B.C. ${ }^{138}$ provides basic information on how to prepare for a negotiation (see Figure 13). ${ }^{139}$

\section{Figure 13}

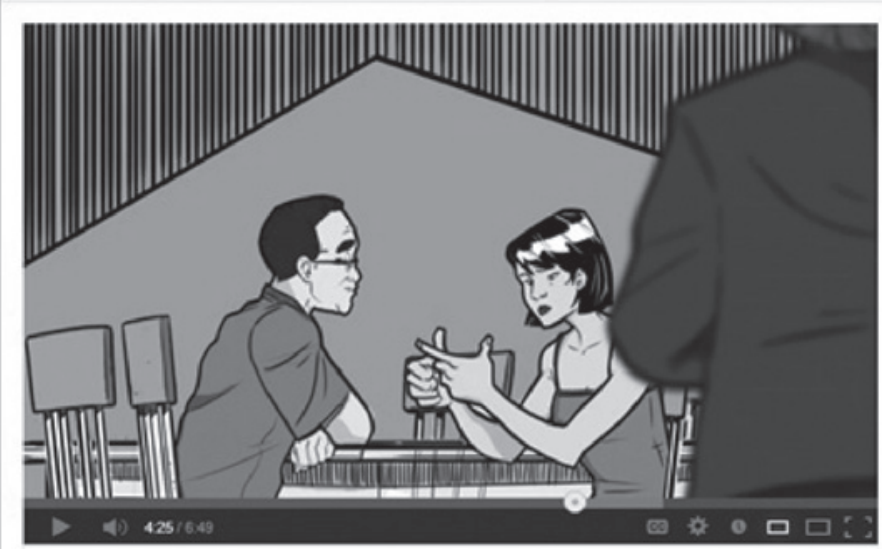

Preparing for a Tough Talk

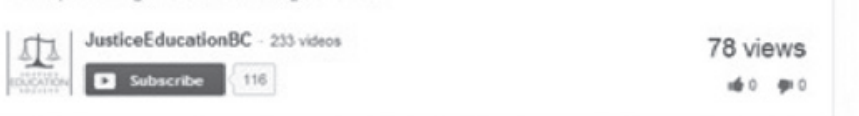

Screenshot (at 4:25) from 'Preparing for a Tough Talk' Video ${ }^{140}$

To facilitate communication or early negotiation between the parties in a dispute, the JPES could offer a letter template tool. Because the system would have previ-

134 Macfarlane, 2013, at p. 35.

135 Id. Macfarlane cites early use of this term in finance and economics from E. Walker, 'Disintermediation and Its Effect on the Stability and Savings Capital at Financial Institutions', Studies in Economics and Finance, Vol. 3, No. 1, 1979, p. 63.

136 Susskind, 2008, p. 271.

137 Macfarlane, 2013, p. 63 citing to videos from the Justice Education Society of B.C, available from <www.justiceeducation.ca/resources/videos>.

138 Justice Education Society of B.C., 'Videos', available from <www.justiceeducation.ca/resources/ videos>.

139 Justice Education Society of B.C., 'Preparing for a Tough Talk', YouTube Video, 2012. Retrieved on 27 July 2013 from <www.YouTube.com/watch?v=Ms5FK3ta_SI>.

$140 \mathrm{Id}$. 
ously diagnosed the user's type of problem, this template could be delivered with very specific content to address the circumstances. For example, in a consumer dispute, the customized template could set out the problem or concern, along with relevant details that will be important to the seller, accompanied by proposals for further steps in the resolution process. ${ }^{141}$

While letter templates may seem simplistic to lawyers and dispute resolution professionals, an inexperienced user may derive considerable benefit from the tool. Based on his experience with the Rechtwijzer system, Jelle van Veenen has observed that letters and email can serve multiple purposes, including: improving communication in the context of a dispute; encouraging the user to reflect on the conflict from the perspectives of all parties and assisting the user to express the problem and its consequences to the other party effectively. ${ }^{142}$

In our JPES loan and debt example, a letter could be used in combination with calculator self-help tools. One calculator could help our user, who experiences financial problems, start by determining her monthly disposable income (see Figure 14).

\section{Figure 14}

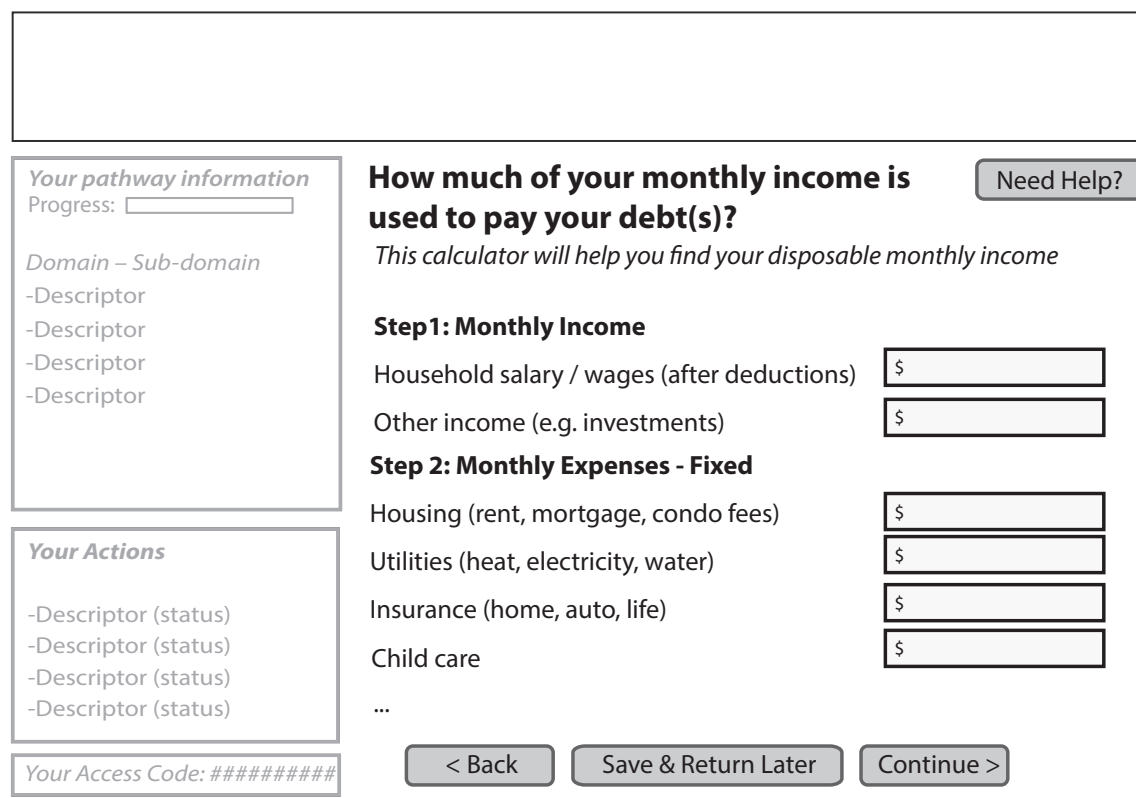

JPES Screenshot - Monthly Disposable Income Calculator

A subsequent calculator could help determine a realistic repayment amount for a loan or debt (see Figure 15).

141 Veenen, 2008, p. 28.

142 Id. 


\section{Figure 15}

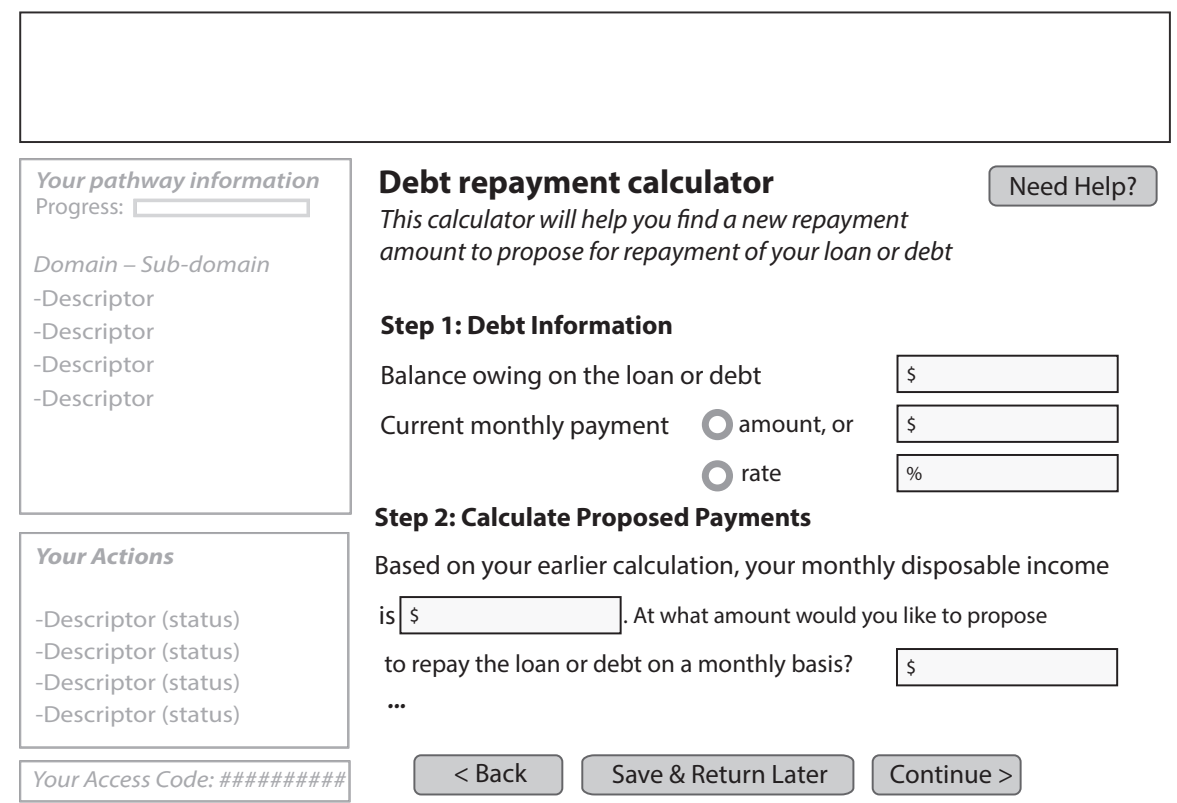

JPES Screenshot - Debt Repayment Calculator

Once our user has used the calculators to determine a proposed repayment amount that corresponds reasonably with a portion of her disposable monthly income, the system could then provide a partially populated letter template in real text format to be completed and saved locally for attachment to an email or printing and mailing (see Figure 16).

Similar templates could be used for a variety of dispute types and purposes, up to and including the recommended structure for capturing agreements between the parties.

For a visual record and easy reference, various self-help tools offered to the user in the pathway can be displayed in a status box in the bottom left quadrant of the screen (see Figure 17).

Depending on the recommendations of subject matter experts, the JPES can provide a variety of tools for each pathway (see Figure 18).

Even if self-help tools do not achieve an early resolution in every case, research suggests that users, nevertheless, prefer dispute resolution processes in which they feel a sense of control. ${ }^{143}$ In the early stages of a dispute, the JPES could offer a degree of control to users, and equip them with dispute management tools designed and recommended by experts in their fields. 


\section{Figure 16}

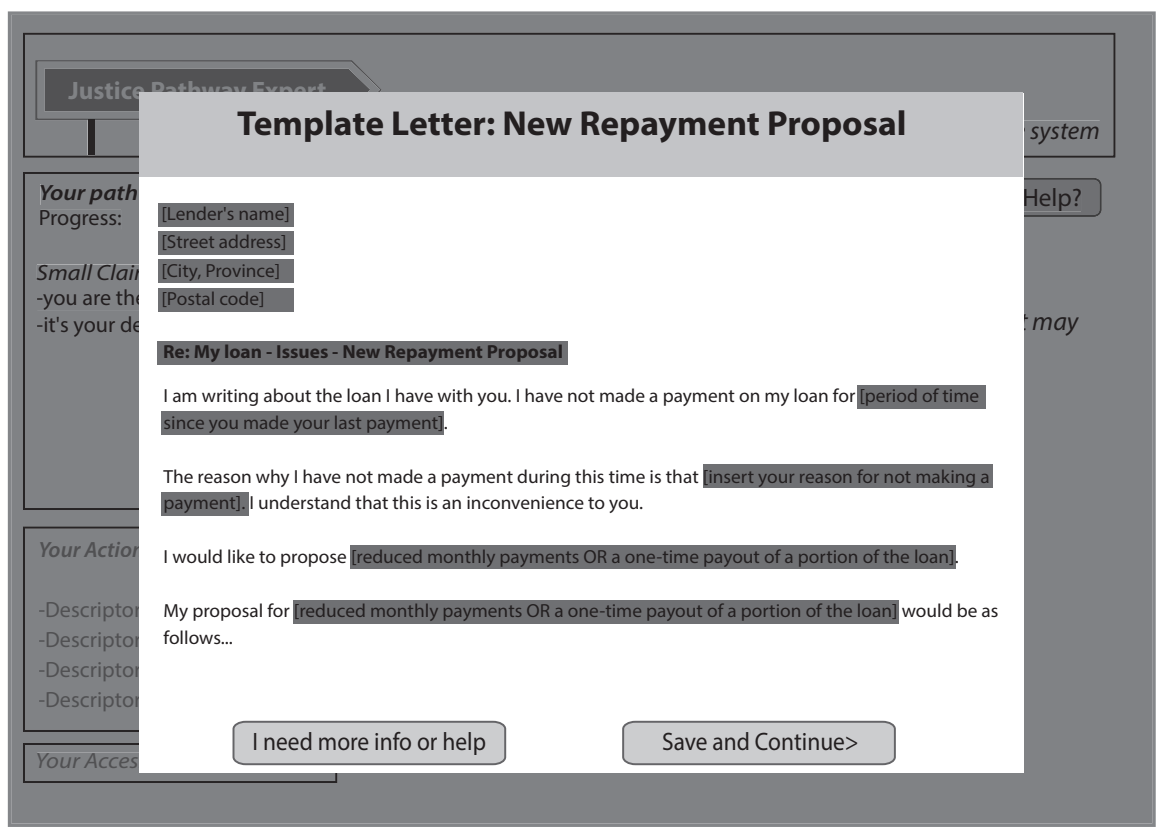

JPES Screenshot - Repayment Proposal Letter Template

\subsection{Streaming and Triage}

As the user nears completion of the JPES pathway, functions will shift towards preparation for successive dispute resolution phases. This collection of functions can be called streaming and triage.

Depending on the linkage between the JPES and subsequent phases, it may be necessary to provide guidance in selecting the appropriate specialized stream or process. In a court process, for example, it could be a matter of filing pleadings, perhaps with the assistance of an online filing assistant. ${ }^{144}$

In an ODR process, streaming functions could move the user into a party-toparty online negotiation or facilitated dispute resolution process similar to systems used by eBay and PayPal for handling 60 million disputes annually. ${ }^{145}$ Orna Rabinovich-Einy and Ethan Katsh observe that more sophisticated systems might include automated negotiation where software assumes an active role, replacing

144 See, e.g., the British Columbia Small Claims Court, 'Filing Assistant Tool'. Retrieved on 5 May 2015 from <https://justice.gov.bc.ca/FilingAssistant/index.do;jsessionid=vB4IieHjqAzibO5JDKY EVzVN.filingassistant-jbosspub0prd $>$.

145 S. Cooper, C. Rule \& L.F. Del Duca, 'From Lex Mercatoria to Online Dispute Resolution: Lessons From History in Building Cross-Border Redress Systems', Uniform Commercial Code Law Journal, Vol. 43, 2011, p. 2. Retrieved on 22 July 2013 from <http://ssrn.com/abstract=1840572>. 


\section{Figure 17}

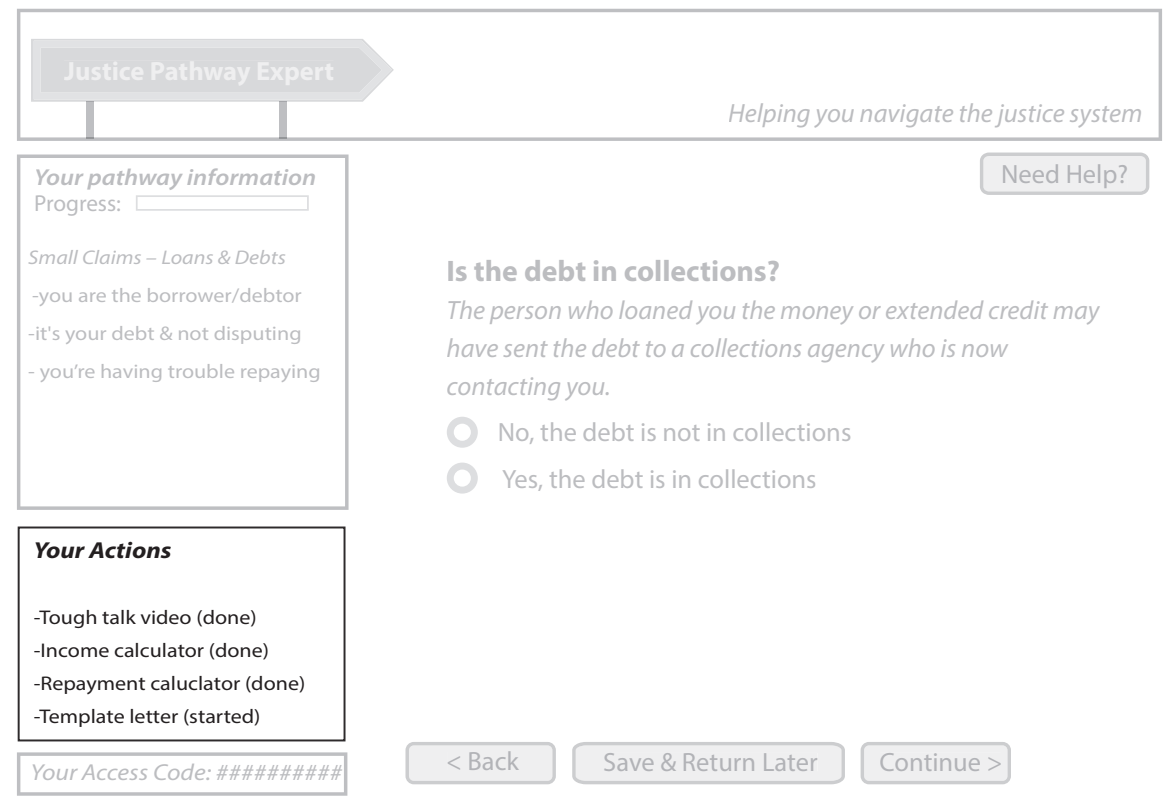

JPES Partial Screenshot - Actions Box

human third-party mediators and arbitrators. ${ }^{146}$ Similarly, Arno Lodder and John Zeleznikow have advocated systems that provide moderately advanced negotiation, argumentation and decision support functions. ${ }^{147}$ Detailing the full range of ODR streaming possibilities is beyond the scope of this article. However, many options exist for streaming users into subsequent ODR processes. ${ }^{148}$

The triage function can be applied to identify appropriate steps or services based on the user's needs and circumstances. ${ }^{149}$ For example, a user identified as having a high level of need could be directed to a public legal education and information provider for assistance. Similarly, a user wanting to retain a lawyer could

146 O. Rabinovich-Einy \& E. Katsh, 'Lessons From Online Dispute Resolution for Dispute Systems Design', in M.A. Wahab, E. Katsh \& D. Rainey (Eds.), Online Dispute Resolution: Theory and Practice: A Treatise on Technology and Dispute Resolution, Eleven International Publishing, The Hague, 2012, pp. 51, 53.

147 See, e.g., Lodder \& Zeleznikow, 2012.

148 For a recent overview of the variety of ODR processes, see M.A. Wahab, E. Katsh \& D. Rainey (Eds.), Online Dispute Resolution: Theory and Practice, A Treatise on Technology and Dispute Resolution, Eleven International Publishing, The Hague, 2012.

149 Federation of Law Societies of Canada, National Action Committee on Access to Justice in Civil \& Family Matters, Prevention, Triage and Referral Working Group, 'Consultation Paper on Prevention, Triage and Referral Processes: Description of Problem and Plan of Action', 2012, p. 7. Retrieved on 22 July 2013 from <www.cfcj-fcjc.org/sites/default/files/docs/2012/Preliminary \%20PTR\%20Report\%20(2012-06-04).pdf > 


\section{Figure 18}

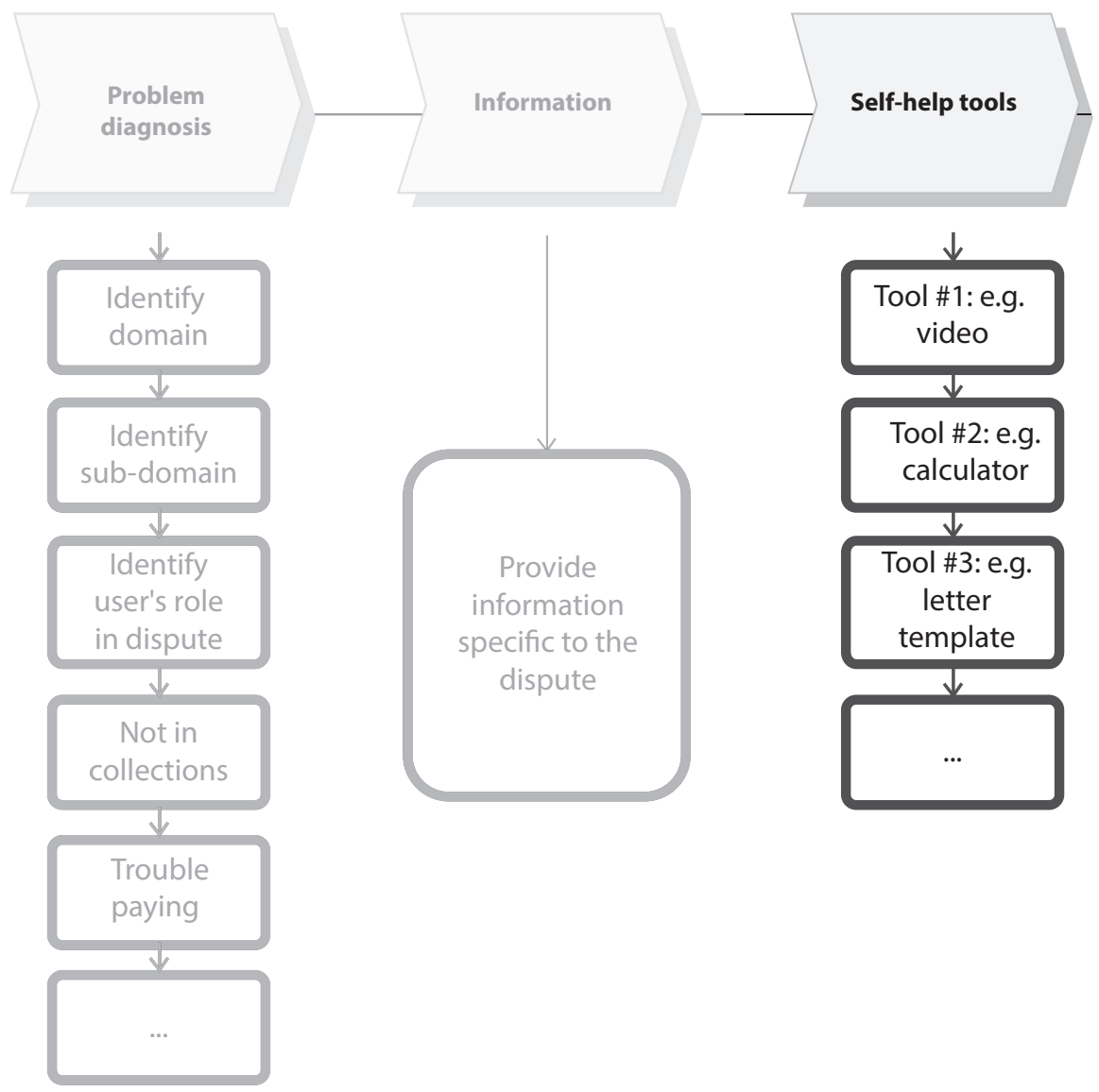

Functional Overview - Self-Help Tools

be directed to a referral service. ${ }^{150}$ People with language, literacy or technology challenges could be directed to facilitators or paid intermediaries. Distraught users or people with mental health problems could be directed to counseling or more specialized mental health triage processes (see Figure 19).

From an accessibility perspective, the aim of triage is to bring together a variety of available resources in a single place. ${ }^{151}$ Moreover, these resources ought to be specifically targeted to provide the greatest benefit to each individual user. ${ }^{152}$

150 See, e.g., the Canadian Bar Association British Columbia Branch, 'Lawyer Referral Service'. Retrieved on 5 May 2015 from <http://cbabc.org/Advocacy/Initiatives/Lawyer-Referral-Service>.

151 Cabral et al., 2012, p. 293.

$152 \mathrm{Id}$. 


\section{Figure 19}

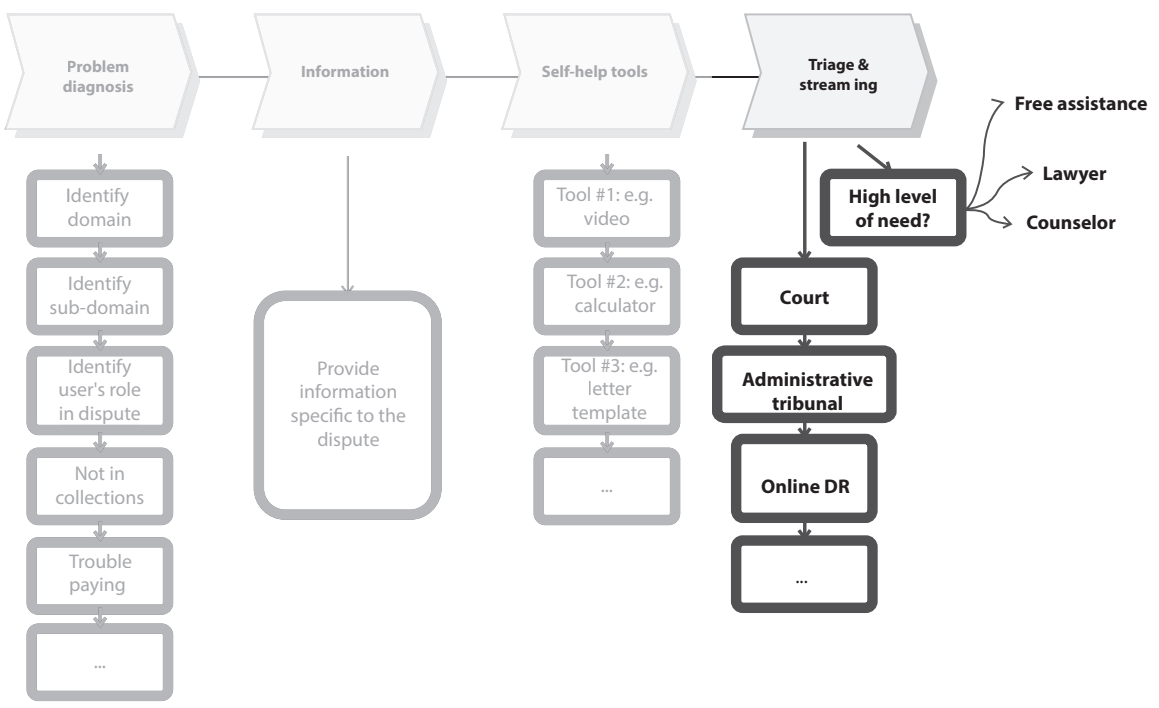

Functional Overview - Streaming and Triage

After a user with an ongoing dispute has been streamed into another process, the JPES pathway would end. At this point, the system could provide a report summarizing the pathway, including reference to the diagnosis, information, selfhelp, emotional intelligence (discussed later) and streaming and triage experiences for that user (see Figure 20).

Presumably, some of the user's information could be stored temporarily in the system for retrieval or review purposes.

This section provides an overview of methods for identifying, acquiring and structuring expert knowledge for the JPES.

\subsection{Identifying the Knowledge Domain}

While the JPES is a justice expert system, it will neither perform at the level of a lawyer nor focus exclusively on the practice of law. ${ }^{153}$ It will engage a much wider scope that also includes elements of problem or dispute management, dispute resolution and emotional intelligence. 
Figure 20

\begin{tabular}{|c|}
\hline $\begin{array}{r}\text { Justice Pathway Expert } \\
\end{array}$ \\
\hline Congratulations! You are managing your problem. Here is your summary report: \\
\hline $\begin{array}{l}\text { Diagnosis } \\
\text { You have a problem with a debt. You are the debtor, or the person who owes money to someone. The } \\
\text { debt is not in collections. You are not disputing the debt, but are having trouble repaying... }\end{array}$ \\
\hline $\begin{array}{l}\text { Information } \\
\text { People who have trouble repaying debts are sometimes able to renegotiate the payment amounts or } \\
\text { schedules with the person who made the loan. There is no guarantee that this option will work, but it... }\end{array}$ \\
\hline $\begin{array}{l}\text { Tools } \\
\text { •Monthly budgeting tool (here) } \\
\text { •Repayment schedule tool (here)... }\end{array}$ \\
\hline
\end{tabular}

\section{How are you feeling?}

Many people find debt problems to be stressful. You are handling it well, and have begun to use the self-management strategies explained in the video called "Dealing with Debt - Life Goes On"...

\section{Next Steps}

If the lender doesn't accept your new proposal, you can negotiate through an online, completely private 'room' created especially for this type of dispute. If this happens, we'll send you the instructions on...

JPES Screenshot - Personalized Summary Report

The aspirations of any knowledge base are limited by width and depth. ${ }^{154}$ In terms of width, the knowledge engineers must identify limits to the scope of subject matter for which it can provide expert knowledge. ${ }^{155}$ In the justice context, a useful approach begins with broad alignment to jurisdictions of courts or tribunals. In B.C., a high-level distinction could be made between civil and criminal matters. Within the civil jurisdiction, family and non-family disputes can be distinguished. Within non-family disputes, a separation could be made between the jurisdiction of the B.C. Supreme Court and the Small Claims Court ${ }^{156}$ with its $\$ 25,000$ limit. ${ }^{157}$

The B.C. Small Claims jurisdiction is an appropriate domain for the JPES. Within this jurisdiction, it is possible to identify relatively discrete subdomains or

154 Grosso et al., 'Knowledge Modeling at the Millennium: The Design and Evolution of Protégé 2000', Stanford University Medical Informatics Technical Report, SMI-1999-0801, 1999, pp. 3-4.

155 Lodder \& Zeleznikow, 2005, p. 291.

156 See, e.g., the B.C. Small Claims Act, RSBC 1996, Chapter 430, Part 1, Section 3, on 'Claims the Court May Hear'. Retrieved on 5 May 2015 from <www.bclaws.ca/Recon/document/ID/freeside/ 00_96430_01\#section3>.

157 See the Monetary Limit Regulation to the B.C. Small Claims Act, B.C. Reg. 179/2005, Section 1, 2005. Retrieved on 5 May 2015 from <www.bclaws.ca/civix/document/id/complete/statreg/179_ 2005>. 
dispute types. For instance, the knowledge base would include consumer, business to business, employment, loan and debt, injury and accident, insurance, personal property and real estate disputes. ${ }^{158}$ Identifying these categories could be a mid-level exercise that corresponds to the beginning of different pathways through the knowledge domain (see Figure 21).

\section{Figure 21}

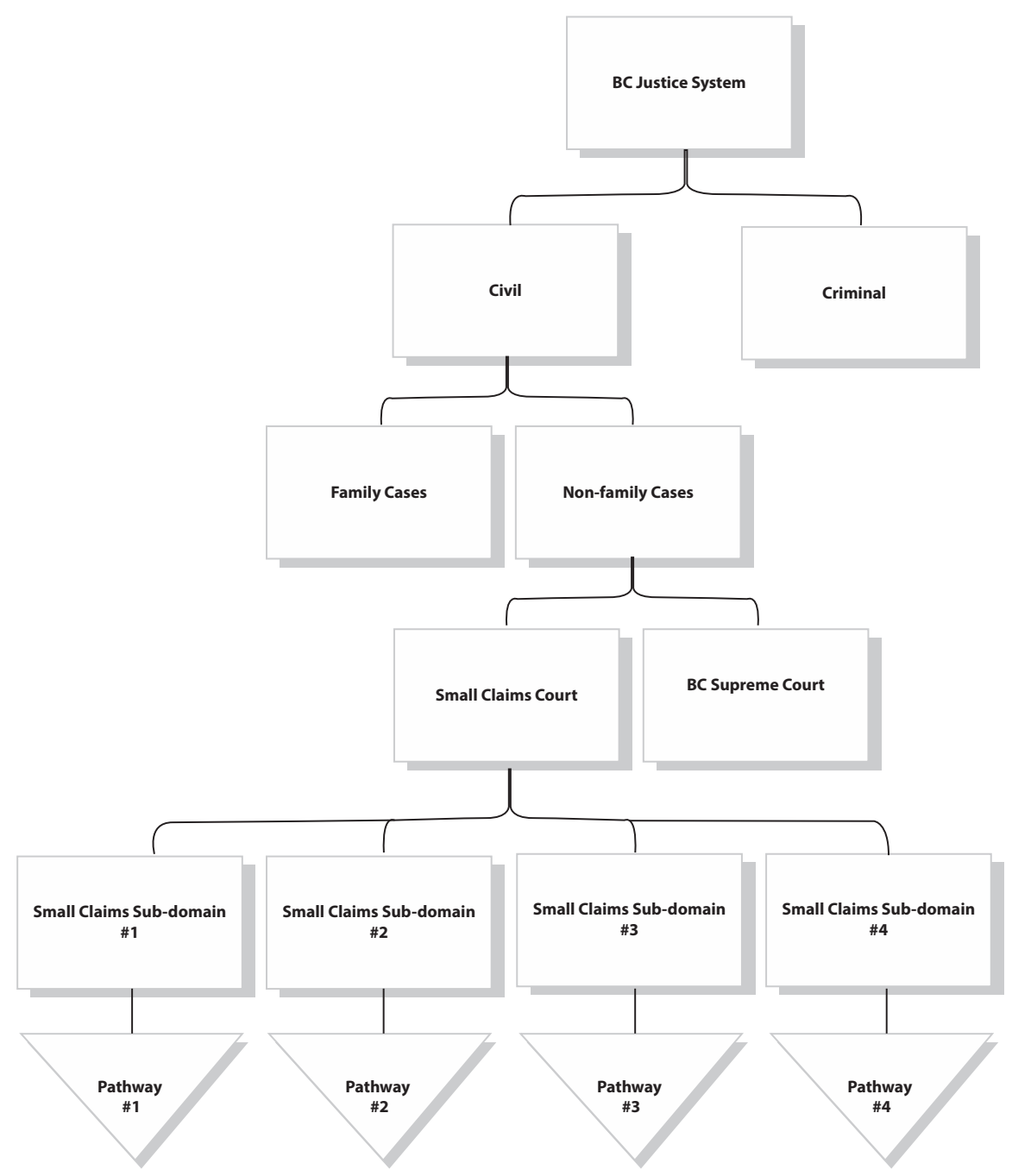

Identification of the Small Claims Subdomains to Pathway Levels

158 This categorization corresponds closely to case type categories in British Columbia Ministry of Attorney General, 'Evaluation of the Small Claims Court Pilot Project - Final Report' (Focus Consultants, B.C. 2009) in Table 14, p 24. 
With respect to depth of a knowledge base, variances may exist in the degree of specialization for various case types. For example, a small claims case identified as a loan and debt dispute would first be identified as falling within the $\$ 25,000$ limit. It could further be identified as a loan from someone in the business of lending (as opposed to a personal loan), and more particularly as a loan from a payday lender whose activities are regulated by legislation. ${ }^{159}$ Other case types may be characterized with less specificity.

Moving deeper into the knowledge domain results in the formation of the actual JPES pathways. The pathways are structured in decision tree logic diagrams, which are analytical tools used to represent multistage decision processes. ${ }^{160}$ The intersections of each 'branch' correspond to the system's question screens, with the branches showing the production rules that fire when selected by a user.

This knowledge modelling approach supports the JPES's system design goals. As a working methodology, it has the capacity to diagnose problems, and to deliver specific information, assistance and feedback to users through its pathway approach.

\subsection{Knowledge Engineering}

Expert knowledge is fundamentally important to the JPES. ${ }^{161}$ It consists not only of facts within the justice domain, but also of heuristic knowledge, embracing rules of expertise, judgment and practice. ${ }^{162}$ Knowledge engineering is the process by which this knowledge is acquired for the knowledge base. ${ }^{163}$ Edward Feigenbaum has also characterized the activity as 'expertise modeling'. ${ }^{164}$

The knowledge base is built through acquisition of expert knowledge within the subject domain. It is then modeled to create the JPES pathways. Because the system is rule-based, the knowledge must be encoded into rules. ${ }^{165}$ Once it has been modelled, it can be programmed into the system. These combined efforts require considerable levels of expertise, a uniform methodological approach and some programming effort. ${ }^{166}$

The knowledge engineers who conduct these activities serve as intermediaries between domain experts and the knowledge base itself. ${ }^{167}$ The activities of knowledge engineers include interviewing experts to elicit the knowledge and encoding

159 In B.C. for example, see Part 6.1 of the Business Practices and Consumer Protection Act, SBC 2004, Chapter 2.

160 E. Chrysler, 'Using Decision Tree Analysis to Develop an Expert System', Information Systems Education Journal, Vol. 4, 2006, pp. 1, 3.

161 Engelmore \& Feigenbaum, 1993.

162 Feigenbaum, 1984, p. 91.

163 B.R. Gaines \& M. Shaw, 'Eliciting Knowledge and Transferring It Effectively to a KnowledgeBased System', IEEE Transactions on Knowledge and Data Engineering, Vol. 5, No. 1, 1993, p. 4.

164 Feigenbaum, 1984, p. 91.

165 Bogacz \& Giraud-Carrier, 1998, pp. 576, 578.

166 D. Ford \& J. Sterman, 'Expert Knowledge Elicitation to Improve Formal and Mental Models', System Dynamics Review, Vol. 14, No. 4, 1998, pp. 309, 310.

167 Gaines \& Shaw, 1993, p. 4. 
it into the knowledge base. ${ }^{168}$ Ultimately, every bit of knowledge must be entered, piece by piece. ${ }^{169}$

The B.C. Ministry of Justice has begun modelling knowledge for the development of its Solution Explorer ${ }^{170}$ system, which holds many similarities to the JPES. The Solution Explorer project team has developed a working methodology for its knowledge engineering ${ }^{171}$ that includes three high-level stages:

1 Expert knowledge gathering workshop.

2 Modelling expert knowledge in a decision tree structure through mind-mapping software.

3 Entering the expert knowledge into the knowledge base in a rule-based format.

The initial knowledge gathering workshop requires a facilitator, serving the role of knowledge engineer, to extract the expert knowledge. J.R. Quinlan has noted that attempting to extract and refine a set of rules through interviews is difficult, given the differences between the way experts express themselves and the way rules must be written. ${ }^{172}$ A primary source of dissonance is thought to be the way human experts express themselves broadly, and assume bits of knowledge upon which conclusions are based. ${ }^{173}$ Accordingly, knowledge engineers can work with experts to extract rules from situational examples or sample problems in the knowledge domain. ${ }^{174}$

Using various facilitation techniques, knowledge engineers lead experts through fact scenarios towards specific actions and outputs, and record the reasoning process in decision trees. The B.C. Ministry of Justice approach has limited the content in its decision trees to questions and answers, supports, actions, alternatives and exit reports. This question-and-answer format will be critical to the functioning of the JPES, serving as the user interface for the conditional rules within the JPES pathways.

The B.C. work has shown that mind-mapping software addresses modelling requirements in the knowledge engineering environment. ${ }^{175}$ The diagram in

$168 \mathrm{Id}$.

169 Engelmore \& Feigenbaum, 1993.

170 The Solution Explorer system is still in its conceptual phase, relating to the development of the British Columbia Civil Resolution Tribunal. For more information, see Civil Resolution Tribunal Act, available from <www.ag.gov.bc.ca/legislation/civil-resolution-tribunal-act/>.

171 B.C. Ministry of Justice, Dispute Resolution Office, 'Knowledge Engineering Guide' (Internal document relating to the Civil Resolution Tribunal 2013), p. 4.

172 J.R. Quinlan, 'Simplifying Decision Trees', International Journal of Man-Machine Studies, Vol. 27, No. 3, 1987, p. 221.

173 D.A. Waterman, A Guide to Expert Systems, 1st edn, Addison-Wesley Publishing, Boston, 1986, p. 153.

174 Quinlan, 1987, p. 221.

175 The B.C. Ministry of Justice has used XMind mind mapping software, available from <www. xmind.net/>. 
Figure 22 shows a decision tree (excerpt) created through knowledge engineering sessions with loan and debt experts. ${ }^{176}$

\section{Figure 22}

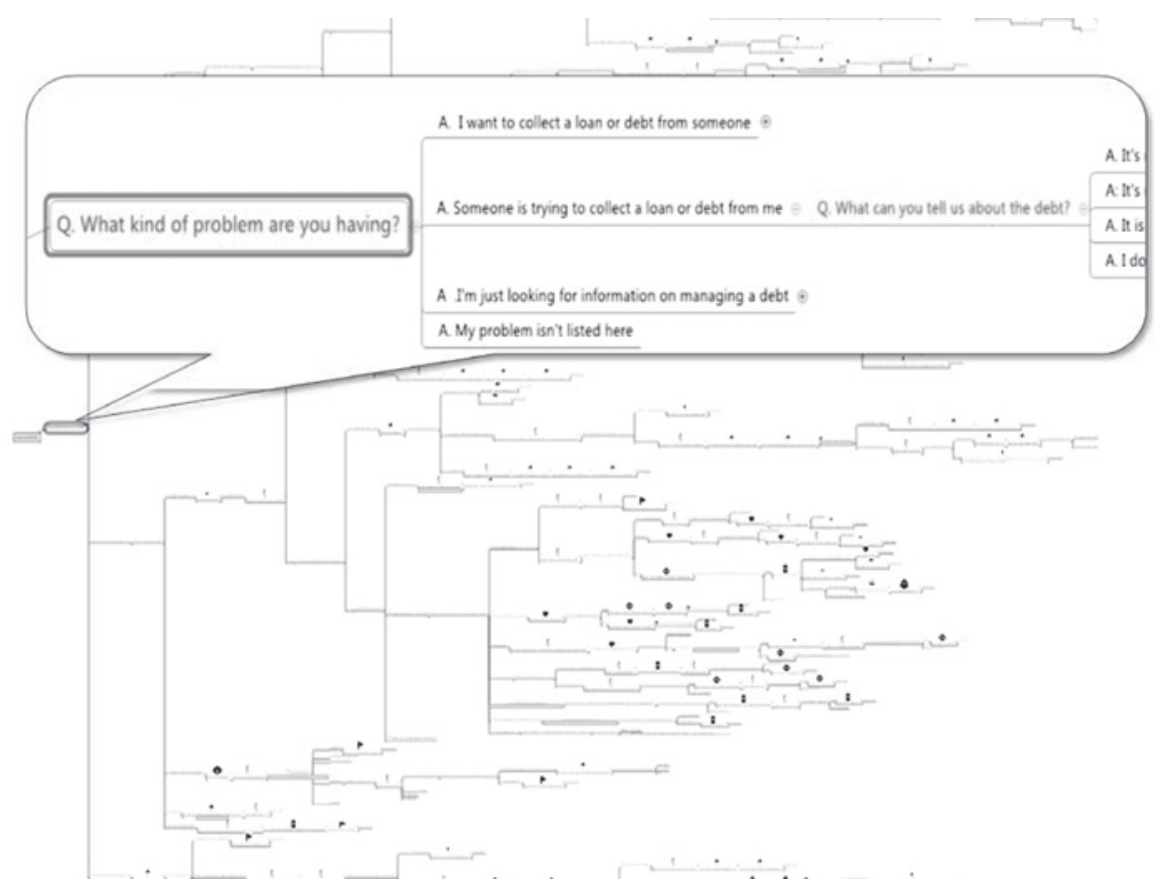

Excerpt - B.C. Ministry of Justice Solution Explorer Expert Knowledge Mind Map

The B.C. Ministry's approach has also been to include 'actions' and 'support' entries in the decision tree. These items correspond with the JPES's 'self-help' and 'information' functions, respectively (see Figure 23).

'Alternatives' are modelled in the knowledge engineering process to indicate avenues away from the JPES to other service providers, such as public legal education and information organizations, credit counselors, debt pooling agencies or lawyers. These 'alternatives' reflect the JPES's 'streaming and triage' functions (see Figure 24).

Exit summary reports (similar to the JPES Screenshot - Personalized Summary Report, above), are denoted in decision trees as 'XSR' at the ends of the pathways.

176 There have been several knowledge modeling sessions involving B.C. Ministry of Justice staff and experts from Consumer Protection B.C. The author has been the project team lead and the facilitator for most of the meetings. 
Figure 23

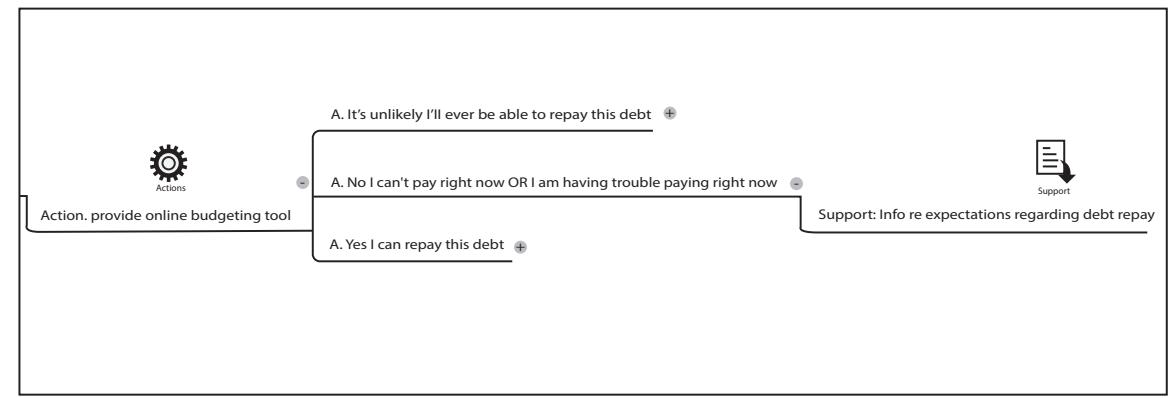

Excerpt - Loan and Debt Pathway - Actions and Support

\section{Figure 24}

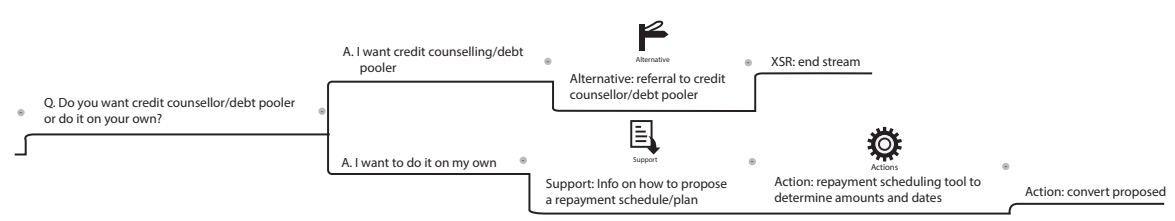

Excerpt - Loan and Debt Pathway - Alternative and Exit Summary Report

\subsection{Populating the JPES Knowledge Base}

Converting knowledge pathways to mind maps in the JPES knowledge base is done through a specific interface. As with most expert systems, the JPES relies on a user-friendly knowledge acquisition utility to facilitate entry and revision of expert knowledge into the knowledge base. ${ }^{177}$ In conceptual terms, this module is an interface between experts and the expert system itself. ${ }^{178}$ Figure 25 shows the JPES Pathway Builder Tool.

The success of the system depends on the administrators' ability to modify and improve the knowledge base during prototyping, testing and use of the system. ${ }^{179}$ Bryan Niblett cites the need for reasonably simple modification of the knowledge base for expert systems in the legal domain, given the changing nature of law and its related norms. ${ }^{180}$ While this may be true to a lesser extent for JPES given its reduced emphasis on legalistic approaches, it may nevertheless be impacted by changes to the law. An easily modifiable knowledge base will support continuous improvement and responsiveness to preferences expressed by actual users.

177 Maher \& Longinos, 1986, p. 9.

$178 \mathrm{Id}$.

179 Luger \& Chakrabarti, 2009, p. 9.

180 B. Niblett, 'Computer Science and Law: An Introductory Discussion', in B. Niblett (Ed.), Computer Science and Law, Cambridge University Press, New York, 1980, p. 17. 


\section{Figure 25}

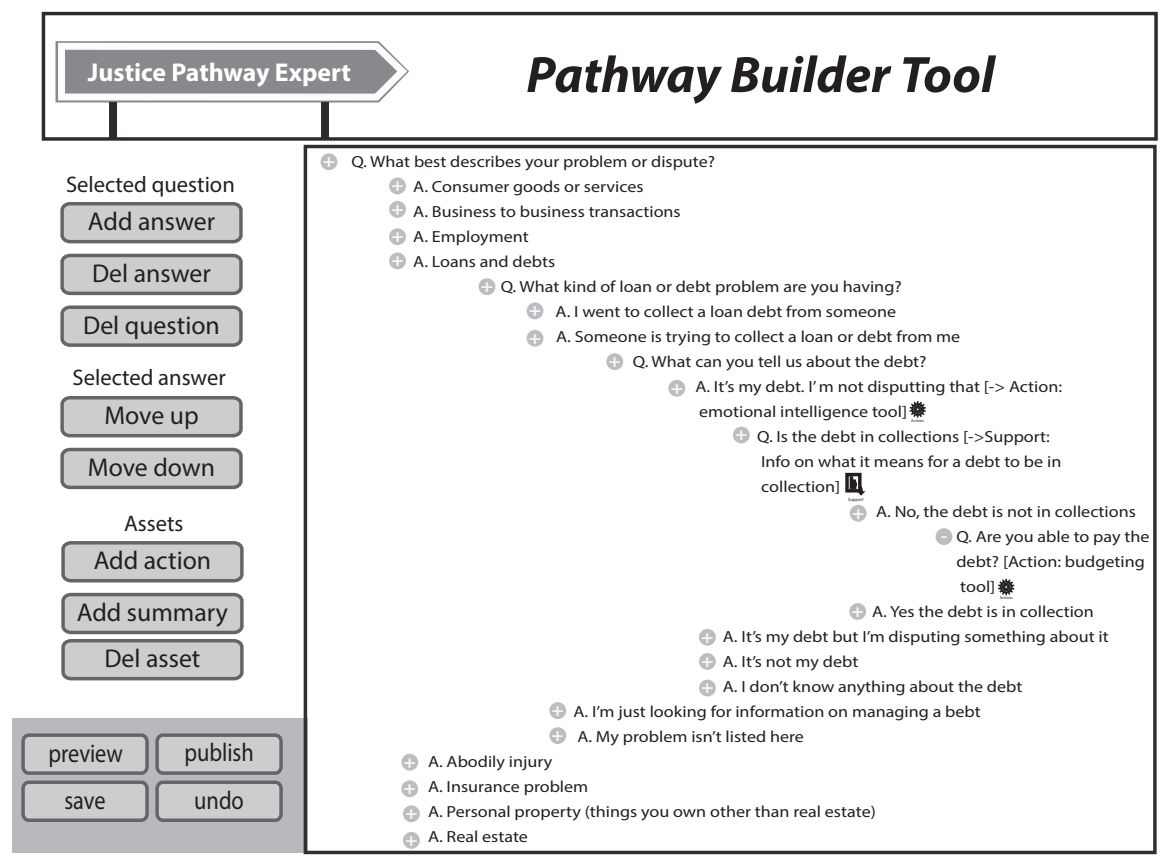

JPES Screenshot - Coding the Knowledge Pathways - Pathway Builder Tool

\section{8}

\section{System Usability}

Breaking through the implementation gap into wider justice system adoption requires a user-friendly expert system. Because issues like user experience design and user acceptance testing are relatively non-subject-specific matters, they will 
not be considered in detail here ${ }^{181}$ other than to acknowledge the Rechtwijzer ${ }^{182}$ as a working example of a system that emphasizes usability through its userfocused co-design process. ${ }^{183}$

Areas that will receive further consideration specific to the JPES are human computer interaction and affective computing, along with proposed 'emotional intelligence' functionality.

\subsection{AI, Human-Computer Interaction and Affective Computing}

Bonnie Rose Hough and Richard Zorza acknowledge that any proposal to supplant human support with computers for justice system triage immediately gives rise to apprehension among stakeholders. ${ }^{184}$ Indeed, the change-resistant culture of most justice systems is especially pronounced when it comes to new technology. ${ }^{185}$ This observation is true for justice system providers such as lawyers, judges and many alternative dispute resolution providers. ${ }^{186}$

A common criticism of technology (particularly in the alternative dispute resolution domain) is a perceived inability to address users' social or emotional needs through computer-based systems. The discipline of human-computer interaction ( $\mathrm{HCI}$ ) provides a starting point for challenging this scepticism. HCI

181 For more information regarding website accessibility, see, e.g., M. Vigo, J. Brown \& V. Conway, 'Benchmarking Web Accessibility Evaluation Tools: Measuring the Harm of Sole Reliance on Automated Tests', Proceedings of the 10th International Cross-Disciplinary Conference on Web Accessibility, W4A 2013, ACM Press, New York, 2013, p. 1; regarding user interface, see, e.g., A. Marcus, 'Cross-Cultural User-Interface Design for Work, Home, Play, and On the Way', Asia, Seoul South Korea Course Handout Notes, SIGGRAPH, 2010, p. 6; D. Fallman, 'Design-oriented HumanComputer Interaction', Proceedings of the SIGCHI Conference on Human Factors in Computing Systems, ACM Press, 2003, p. 225; Vredenburg et al., 'A Survey of User-Centered Design Practice', Proceedings of the SIGCHI Conference on Human Factors in Computing Systems, ACM Press, New York, 2002, p. 471; regarding text simplification, see, e.g., Rello et al., 'Simplify or Help?: Text Simplification Strategies for People with Dyslexia', Proceedings of the 10th International Cross-Disciplinary Conference on Web Accessibility, W4A 2013, ACM Press, New York, 2013, p. 15; regarding user experience, see, e.g., J. Harty, 'Finding Usability Bugs with Automated Tests', Queue Magazine, Vol. 9, No. 1, 12 January 2011. Retrieved on 22 July 2013 from <http://queue.acm.org/ detail.cfm?id=1925091>; regarding usability, see, e.g., A. Holzinger, 'Usability Engineering Methods for Software Developers', Communications of the ACM, Vol. 48, No. 1, 2005, p. 71; E.D. Kock, J.V. Biljon \& M. Pretorius, 'Usability Evaluation Methods: Mind the Gaps', Proceedings of the 2009 Annual Research Conference of the South African Institute of Computer Scientists and Information Technologists, SAICSIT '09, ACM Press, New York, 2009, p. 122; regarding user-centered design, see, e.g., Mao et al., 'The State of User-Centered Design Practice', Communications of the ACM, Vol. 48, No. 3, 2005, p. 105; regarding user-involved design, see, e.g., S. Kujala \& M. Mäntylä, 'Is User Involvement Harmful or Useful in the Early Stages of Product Development', Extended Abstracts on Human Factors in Computing Systems, CHI'00, ACM Press, New York, 2000, p. 285; S. Kujala \& M. Kauppinen, 'Identifying and Selecting Users for User-Centered Design', Proceedings of the Third Nordic Conference on Human-Computer Interaction, NordiCHI '04, ACM Press, New York, 2004, p. 297; Vines et al., 'Configuring Participation: On How We Involve People in Design', Proceedings of the SIGCHI Conference on Human Factors in Computing Systems, CHI '13, ACM Press, New York, 2013, p. 429; Steen et al., 'Co-design: Practices, Challenges and Lessons Learned', Proceedings of the 10th International Conference on Human Computer Interaction with Mobile Devices and Services, MobileHCI '08, ACM Press, New York, 2008, p. 561; J. Pruitt \& J. Grudin, 'Personas: Practice and Theory', Proceedings of the 2003 Conference on Designing for User Experiences, DUX '03, ACM Press, New York, 2003, p. 1. 
explores the way humans interact with technology. ${ }^{187}$ Researchers have found that human-computer interactions follow patterns similar to human-human equivalents. ${ }^{188}$ Users may be aware they are interacting with machines, but still tend to follow human-human social rules, and treat computers as if they have feelings. Humans can become angry towards computers, and may be flattered ${ }^{189}$ or feel praised by them. ${ }^{190}$ Humans recognize computers cannot think or feel emotion, yet still follow human-human social patterns unconsciously. ${ }^{191}$ These manifestations are not limited to systems that take on anthropomorphic characteristics; research suggests they occur even with basic textual interfaces. ${ }^{192}$

Given the potential to address access to justice issues through scalable technology-based systems like the JPES, historical assumptions and opposition must not automatically become barriers to innovation. To make this point in a stronger way, and to demonstrate the multidisciplinary potential for AI and expert systems, the JPES also includes emotional intelligence functionality.

In conflict situations, emotion causes cognitive changes that impact the way we think or act. ${ }^{193}$ It can escalate the severity of a conflict along with the frustrations of the parties. ${ }^{194}$ It can also cause a loss of focus on the issues in a dispute. ${ }^{195}$ A recent study in the Canadian context revealed that the ability of people to use Internet-based access to justice tools and information is impaired by emotional distress. ${ }^{196}$

182 See Rechtwijzer, supra note 89.

183 Hague Institute for the Internationalisation of Law, supra note 90.

184 Cabral et al., 2012, p. 302 citing to Bonnie Rose Hough and Richard Zorza.

185 S.J. Desjardins, 'New Cyber Justice Laboratory to Remedy an Ailing System', UdeMNouvelles, 17 December 2009. Retrieved on 30 July 2013 from <www.nouvelles.umontreal.ca/udem-news/ news/20091217-new-cyber-justice-laboratory-to-remedy-an-ailing-system.html>.

186 Veenen, 2010, p. 4; M. Poblet \& P. Casanovas, 'Emotions in ODR', International Review of Law, Computers \& Technology, Vol. 21, No. 2, 2007, pp. 145, 148; A. Hammond, 'How Do You Write "Yes"?: A Study on the Effectiveness of Online Dispute Resolution', Conflict Resolution Quarterly, Vol. 20, No. 3, 2003, pp. 261, 276.

187 F. Nunes, P.A. Silva \& F. Abrantes, 'Human-Computer Interaction and the Older Adult: An Example Using User Research and Personas', Proceedings of the 3rd International Conference on Pervasive Technologies Related to Assistive Environments, Petra, Greece, ACM Press, New York, 2010, p. 1.

188 P. Mishra, M. Nicholson \& S. Wojcikiewicz, 'Seeing Ourselves in the Computer: Who We Relate to Technologies', Journal of Adolescent \& Adult Literacy, Vol. 44, No. 7, 2001, pp. 634, 636.

189 Id., p. 636.

190 Id.

191 C. Nass \& Y. Moon, 'Machines and Mindlessness: Social Responses to Computers', Journal of Social Issues, Vol. 56, No. 1, 2000, pp. 81, 83.

192 R. Ferdig \& P. Mishra, 'Emotional Responses to Computers: Experiences in Unfairness, Anger, and Spite', Journal of Educational Multimedia and Hypermedia, Vol. 13, No. 2, 2004, pp. 143, 156-157.

193 Boehner et al., 'Affect: From Information to Interaction', Proceedings of the 4th Decennial Conference on Critical Computing: Between Sense and Sensibility, Aarhus, Denmark, ACM Press, New York, 2005, p. 59.

194 B. Zondag \& A.R. Lodder, 'Constructing Computer Assisted Dispute Resolution Systems by Developing a Generic Language to Analyze Information Exchange in Conflict Discourse', International Review of Law Computers \& Technology, Vol. 21, No. 2, 2007, pp. 191, 196.

195 Id., p. 196.

196 Macfarlane, 2013, p. 64. 
The field of affective computing is concerned with "computing that relates to, arises from or deliberately influences emotions". ${ }^{197}$ In the context of HCI, it rejects the notion that people interact with machines only in logical and rational ways, and recognizes affect, or the emotive and human experiential side of computing. Affective computing's direct contribution to the JPES is its rejection of assumptions that the emotional needs of humans can only be met by other humans. ${ }^{198}$

Rosalind Picard observes that affective computing techniques can help to increase emotional awareness and management skills for users. ${ }^{199}$ Some of these interactions can be facilitated by systems that request emotional feedback from users $^{200}$ using a range of techniques including emoticons or defined textual responses.

Jelle van Veenen has also noted that ODR systems can employ questionnaire approaches to help users investigate and better understand their emotions in a dispute, along with the underlying interests to which they relate. ${ }^{201}$ As van Veenen observes, a system can also identify techniques to deal with emotional issues. $^{202}$ Ultimately, the goal is to help users understand their emotional states and the potential impacts they can have on the dispute resolution process. ${ }^{203}$

From a design perspective, JPES's emotional intelligence functionality could help to influence users' perception of their problems or the information communicated to them. ${ }^{204}$ Researchers refer to this phenomenon as 'agenda setting' in the media and communication contexts. ${ }^{205}$ In basic terms, identifying emotional aspects of a dispute as something worthy of consideration helps to impress upon the user that it is important and deserving of some attention or effort. ${ }^{206}$ Viewed from the opposite perspective, a system that ignores the emotional aspects of a dispute may have an inverse effect, ${ }^{207}$ fostering a dispute management approach isolated from the user's emotions. Putting emotions 'on the agenda' is important

197 Scheirer et al., 'Frustrating the User on Purpose: A Step Toward Building an Affective Computer', Interacting with Computers, Vol. 14, No. 2, 2002, p. 93, citing to R.W. Picard, Affective Computing, 1st edn, The MIT Press, 2000.

198 R.W. Picard \& J. Klein, 'Computers That Recognise and Respond to User Emotion: Theoretical and Practical Implications', Interacting with Computers, Vol. 14, No. 2, 2002, p. 141, Available from <www.agent.ai/doc/upload/200605/picard-Computers_that_Recognise_and_Respond_to_ User_Emotion.pdf $>$.

199 Id.

200 R.W. Picard, 'Toward Computers That Recognize and Respond to User Emotion', IBM Systems Journal, Vol. 39, No. 3, 2000, pp. 705, 707.

201 J.V. Veenen, 'Dealing with Miscommunication, Distrust, and Emotions in Online Dispute Resolution', TISCO Working Paper Series on Access to Justice, Dispute Resolution, and Conflict System Design, No. 004/2010, 2010, pp. 31-32. Retrieved on 19 April 2013 from <http://ssrn.com/ abstract $=1626212>$.

202 Id., p. 32.

203 Id.

204 Id., p. 8.

205 Id., p. 10.

206 Id.

207 Id., pp. 10-11. 
because users will be strongly influenced by their feelings in dispute resolution processes in any event. ${ }^{208}$

In our example of the debtor's dispute, the JPES interface for collecting emotional feedback is represented in Figure 26.

\section{Figure 26}

Your pathway information Progress:

Small Claims - Loans \& Debts -you are the borrower/debtor -it's your debt \& not disputing -the debt is not in collections -you're having trouble repaying

Your Actions

-Descriptor (status)

-Descriptor (status)

-Descriptor (status)

-Descriptor (status)

Your Access Code: \#\#\#\#\#\#\#\#\#

\section{How are you feeling about your loan or debt problem?}

When you think about your loan or debt problem, does it make you upset or angry? Drag the slider to a point where it shows how you feel.

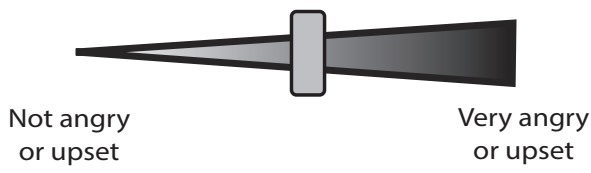

JPES Screenshot - Emotional Intelligence Function

The user's responses to the emotional feedback collection mechanism can be combined with production rules to prompt the JPES to offer support and guidance. For the purposes of the following rules, the emotional feedback mechanism assigns numerical values to various positions on the slider bar. 


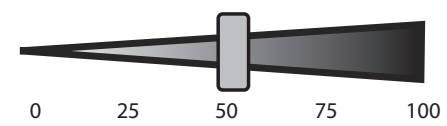

Subdomain question: how are you feeling about your loan or debt problem? (not angry $=0$ / very angry $=100$ )

\begin{tabular}{ll}
\hline Condition & Consequent \\
\hline If (user indicates 0-15) & $\begin{array}{l}\text { then (congratulate user on successful management of } \\
\text { emotions) } \\
\text { then (provide information: benefits of managing emo- } \\
\text { tions) } \\
\text { then (user indicates 16-30) } \\
\text { If (usper indicates 31-45) }\end{array}$ \\
If (user indicates 46-60) & $\begin{array}{l}\text { then (provide information: how to deal with emotional } \\
\text { arousal in disputes) } \\
\text { then (provide information: messages of empathy, shared } \\
\text { If (user indicates 61-75) }\end{array}$ \\
$\begin{array}{l}\text { If (user indicates 76-90) } \\
\text { manage emotions in dispute) }\end{array}$ \\
$\begin{array}{l}\text { then (provide information: benefits of taking a one-hour } \\
\text { break from using system to calm down AND provide } \\
\text { information: messages of empathy, shared experiences in } \\
\text { disputes AND provide video: how to manage emotions } \\
\text { in dispute) } \\
\text { then (provide triage question: resources if you feel you } \\
\text { are in danger or may be likely to take steps you would } \\
\text { regret later AND provide information: benefits of taking } \\
\text { a one-hour break from using system to calm down AND } \\
\text { provide information: messages of empathy, shared expe- } \\
\text { riences in disputes AND provide video: how to manage } \\
\text { emotions in dispute) }\end{array}$ \\
\hline
\end{tabular}

As suggested by the example above, the JPES can rely on emotional feedback to establish that the user's emotional state has been communicated, ${ }^{209}$ and then to reframe it and reflect it back ${ }^{210}$ with appropriate support and guidance.

Users will be sensitive about inaccurate emotional assessments, especially if they are already experiencing high levels of emotional arousal. ${ }^{211}$ Accordingly, an additional step can be included to allow for clarification of emotional feedback to guard against inaccurate assessments (see Figure 28). ${ }^{212}$

209 J. Klein, Y. Moon \& R. Picard, 'This Computer Responds to User Frustration: Theory, Design and Results', Interacting with Computers, Vol. 14, 2002, pp. 119, 125.

210 Id., p. 125.

211 Id.

212 Id. 


\section{Figure 28}

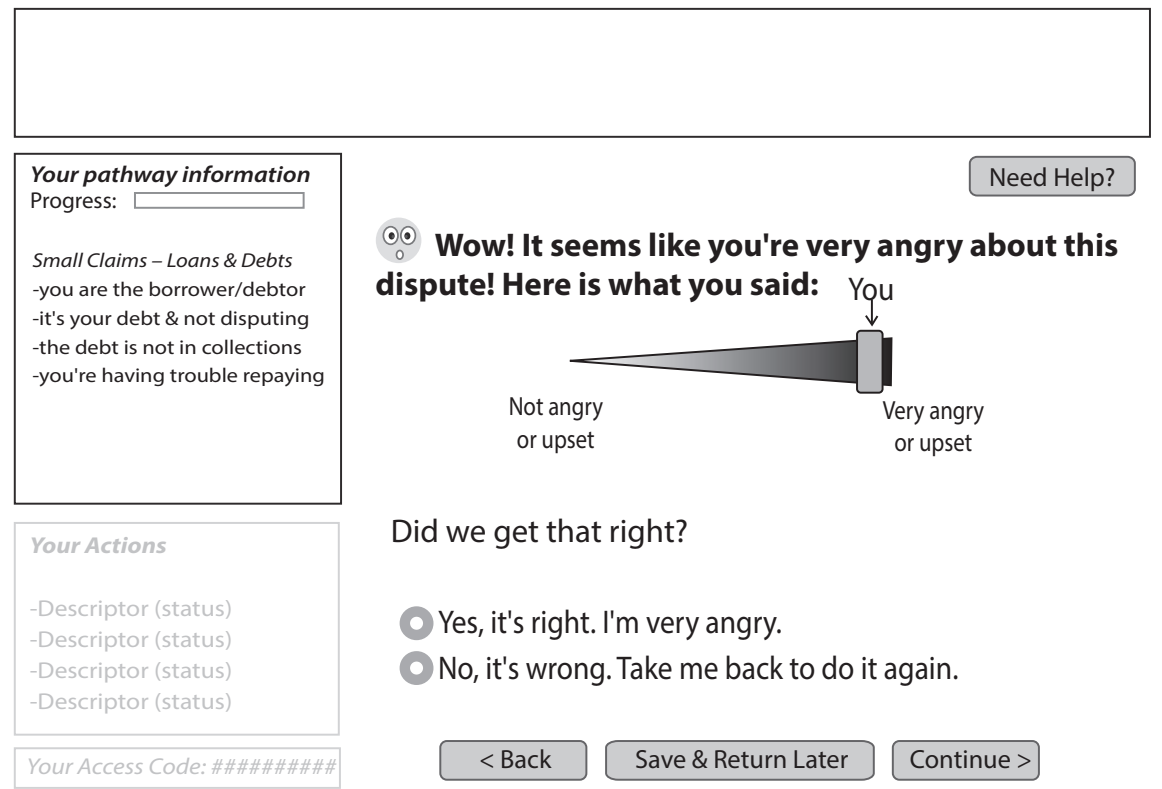

JPES Screenshot - Clarification of Emotional Feedback

To some extent, the JPES imitates the processes of listening and reflection from the ADR context. After emotional feedback is collected and reflected back to the user, the system can convey empathy and sympathy. ${ }^{213}$ Empathy can be conveyed to users by acknowledging the system has 'heard' their emotional feedback. ${ }^{214}$ Sympathy can be conveyed by letting users know their feelings in the dispute have been shared by others, and that they are not unique in experiencing them. ${ }^{215}$ Affective computing research indicates that such expressions of sympathy and empathy can make users feel their emotional states are valid. ${ }^{216}$

In our example of the debtor, emotional feedback indicating high distress levels could prompt the JPES to show a video conveying sympathy and empathy (see Figure 29).

To prevent the JPES from moving too far into a perceived role of counselor, emotional feedback mechanisms are restricted to defined sets of answers or indicators. Limiting these mechanisms will discourage users from disclosing large volumes of sensitive information about their psychological or mental states. Appro- 


\section{Figure 29}

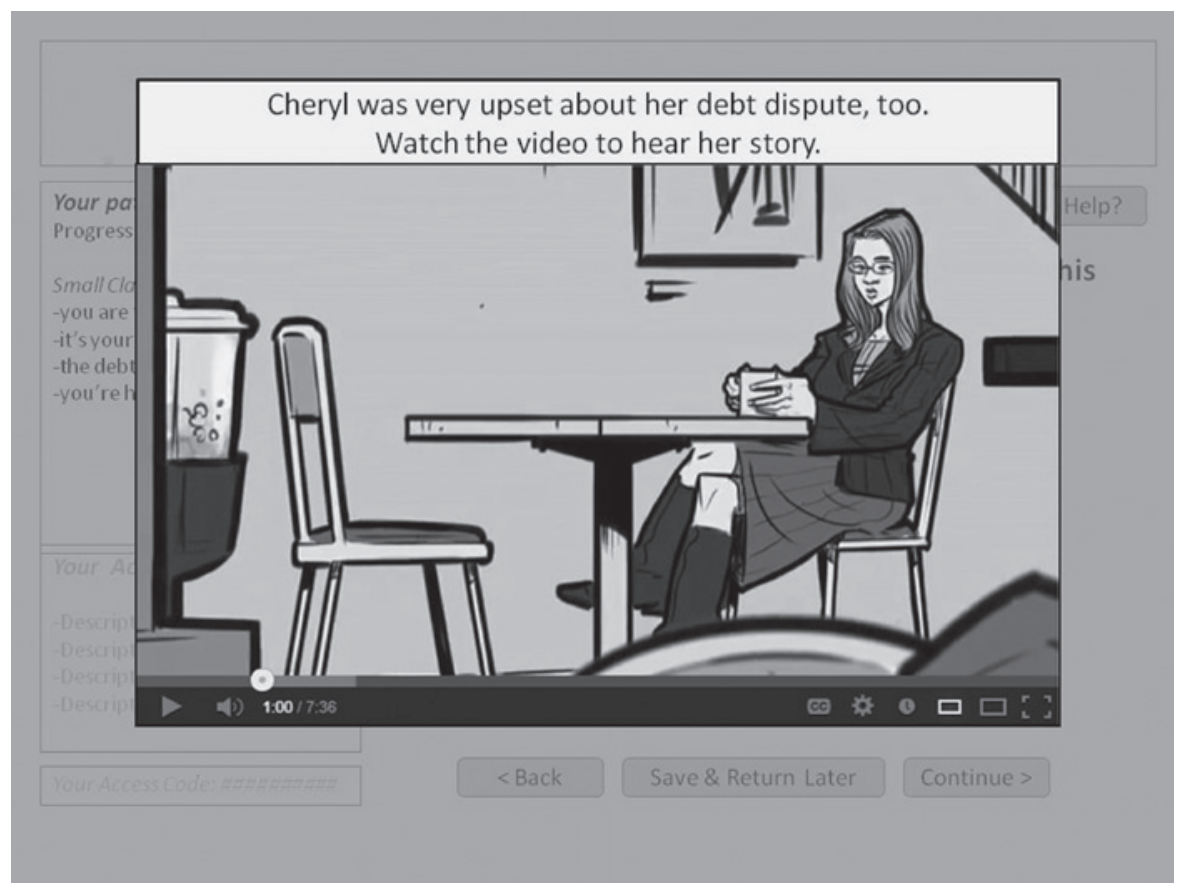

JPES Screenshot - Emotional Intelligence Video

priate protections could also be instituted to protect any information that is disclosed. ${ }^{217}$

AI-based systems can be designed to allow users to enter specific information that can then be analysed for its emotional content. ${ }^{218}$ Berry Zondag and Arno Lodder theorize that disputes can be deconstructed into small units that can then be described on an emotional level. ${ }^{219}$ In their view, these objectives could be accomplished through an automated questionnaire or with semantic analysis technology capable of deriving 'meaning' from free text input by the user. In the case of a less sophisticated system like the JPES, it is still possible to provide basic emotional assistance to users. 220

Emotional intelligence functions can be modeled within the JPES pathways as follows (see Figure 30).

217 For example, in B.C. the information could be excluded from freedom of information requests under the Freedom of Information and Protection of Privacy Act, RSBC 1996, Chapter 165. Retrieved on 6 May 2015 from <www.bclaws.ca/Recon/document/ID/freeside/96165_00>.

218 Zondag \& Lodder, 2007, p. 199.

219 Id.

220 Id., p. 200 
Figure 30

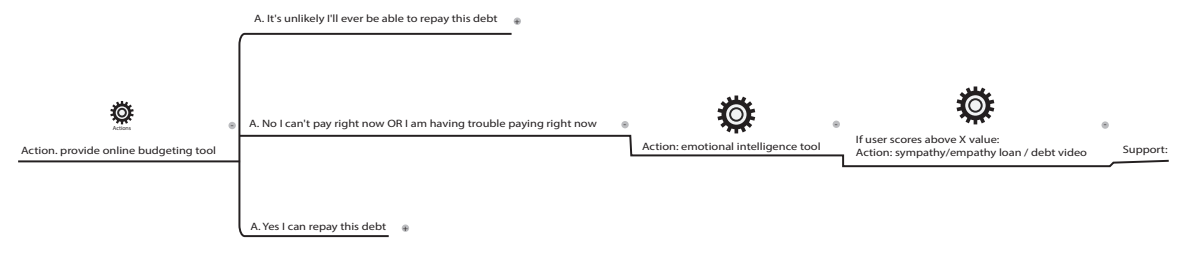

Excerpt - Loan and Debt Pathway - Emotional Intelligence

As an information collection tool, the JPES could accumulate data about responses to the emotional feedback mechanisms. This data can be analysed to compile general profiles of users' emotional states at various points in the pathways and to provide insights into potential enhancements of emotional intelligence functionality. ${ }^{221}$

The emotional intelligence functionality demonstrates the capacity for an expert system to leverage multidisciplinary approaches in the justice context. The JPES pathways will lead users through areas traditional court processes do not, and offer guidance traditional stakeholders may consider irrelevant or inappropriate. HCI and affective computing techniques leverage technology to redefine these justice practices in the same way technology has redefined the way we communicate and interact with one another. ${ }^{222}$

From a more general standpoint, this brief introduction to $\mathrm{HCI}$ and affective computing should challenge assertions that computer-mediated communication is always inferior to its face-to-face equivalent. ${ }^{223}$ Interactions with technologies can increase emotional self-awareness and management for users. ${ }^{224}$ Even if initial versions of the JPES do not feature advanced levels of emotional interactivity, users may still derive benefit from the fact that their emotions have been acknowledged and incorporated into the dispute management and resolution process. ${ }^{225}$ As Leah Wing and Daniel Rainey observe, we have already begun to use the Internet to build relationships, negotiate and even resolve our disputes. ${ }^{226}$ As a branch of ODR, the JPES can support this change in the justice context.

\subsection{Explanation Modules}

To reduce the likelihood that users perceive the JPES's inner workings as a 'black box' shrouded in mystery, a pathway progress tracking utility is included in the

221 Rabinovich-Einy \& Katsh, 2012, p. 61.

222 L. Wing \& D. Rainey, 'Online Dispute Resolution and the Development of Theory', in M.A. Wahab, E. Katsh \& D. Rainey (Eds.), Online Dispute Resolution: Theory and Practice: A Treatise on Technology and Dispute Resolution, Eleven International Publishing, The Hague, 2012, pp. 35, 48.

223 Poblet \& Casanovas, 2007, pp. 148-149; Veenen, 2012, p. 4.

224 Picard \& Klein, 2002, pp. 4-5.

225 Klein et al., 2002, p. 125.

226 Wing \& Rainey, 2012, pp. 49-50. 
Figure 31

\section{Your pathway information}

Progress:

Small Claims - Loans \& Debts

-you are the borrower/debtor

-it's your debt \& not disputing

-the debt is not in collections

-you're having trouble repaying

Not angry

or upset

Your Actions

Did we get that

-Descriptor (status)

-Descriptor (status)

-Descriptor (status)

-Descriptor (status)

Your Access Code: \#\#\#\#\#\#\#\#\#

JPES Partial Screenshot - Pathway Progress

left quadrant of the user interface. This component will help users review their progress along a pathway (see Figure 31). 
This approach is a simplified version of an 'explanation module' often included in expert systems to provide validations or justifications of the reasoning process. ${ }^{227}$ While advanced expert systems use explanation modules as 'audit trails' to reveal bugs or errors, it is not common to provide detailed explanations to users. ${ }^{228}$

The JPES's simple 'Pathway Progress' function will help users understand how they navigated various pathways and show how they progressed through the knowledge base. ${ }^{229}$ Offering these entries in clickable links also allows users to return to specific questions, correct answers and potentially to move into different pathways.

\section{$9 \quad$ Conclusion}

This conceptual description of the JPES demonstrates the potential for AI-based expert systems to support non-lawyer users within the justice context. Expert systems can leverage multidisciplinary expert knowledge and intelligent questionnaires to provide a range of functions and guidance along domain-specific pathways determined by users' individual circumstances. Although the JPES approach is less technically sophisticated than prior AI systems in the justice domain, it nevertheless represents an advanced tool that also offers significant contributions to the field of ODR.

227 Maher \& Longinos, 1986, p. 9.

228 W. Clancey \& E. Shortliffe, 'Introduction: Medical Artificial Intelligence Programs', in W. Clancey \& E. Shortliffe (Eds.), Readings in Medical Artificial Intelligence: The First Decade, Addison-Wesley Publishing, Reading, 1984, p. 11.

229 Cabral et al., 2012, p. 302. 